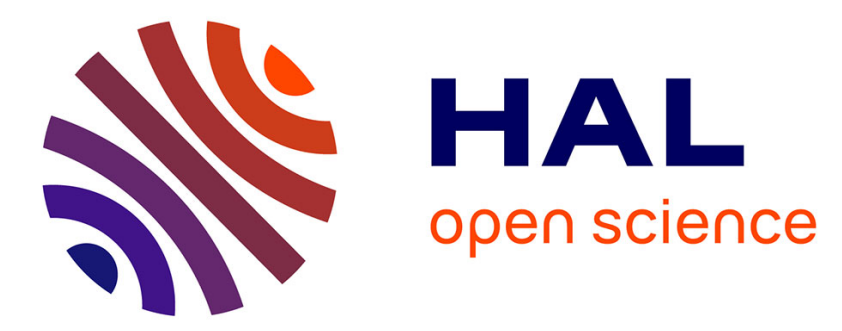

\title{
Large contribution of water-insoluble secondary organic aerosols in the region of Paris (France) during wintertime
}

Jean Sciare, Odile d'Argouges, Roland Sarda-Esteve, Cécile Gaimoz, Cristina Dolgorouky, Nicolas Bonnaire, Olivier Favez, Bernard Bonsang, Valérie Gros

\section{To cite this version:}

Jean Sciare, Odile d'Argouges, Roland Sarda-Esteve, Cécile Gaimoz, Cristina Dolgorouky, et al.. Large contribution of water-insoluble secondary organic aerosols in the region of Paris (France) during wintertime. Journal of Geophysical Research: Atmospheres, 2011, 116, pp.D22203. 10.1029/2011JD015756 . ineris-00963327

\section{HAL Id: ineris-00963327 \\ https://hal-ineris.archives-ouvertes.fr/ineris-00963327}

Submitted on 6 May 2021

HAL is a multi-disciplinary open access archive for the deposit and dissemination of scientific research documents, whether they are published or not. The documents may come from teaching and research institutions in France or abroad, or from public or private research centers.
L'archive ouverte pluridisciplinaire HAL, est destinée au dépôt et à la diffusion de documents scientifiques de niveau recherche, publiés ou non, émanant des établissements d'enseignement et de recherche français ou étrangers, des laboratoires publics ou privés. 


\title{
Large contribution of water-insoluble secondary organic aerosols in the region of Paris (France) during wintertime
}

\author{
Jean Sciare, ${ }^{1}$ Odile d'Argouges, ${ }^{1}$ Roland Sarda-Estève, ${ }^{1}$ Cécile Gaimoz, ${ }^{1}$ \\ Cristina Dolgorouky, ${ }^{1}$ Nicolas Bonnaire, ${ }^{1}$ Olivier Favez, ${ }^{2}$ Bernard Bonsang, ${ }^{1}$ \\ and Valérie Gros ${ }^{1}$ \\ Received 1 February 2011; revised 10 August 2011; accepted 21 September 2011; published 17 November 2011.
}

[1] Near real-time measurements of carbonaceous aerosols were performed in fine aerosols for a 10-day period during winter at a suburban site of Paris (France). These measurements were performed using an OCEC Sunset Field instrument for elemental carbon (EC) and organic carbon (OC); a Particle-Into-Liquid-Sampler coupled with a Total Organic Carbon (PILS-TOC) instrument for water-soluble OC (WSOC); and a 7- $\lambda$ aethalometer for absorption. A successful comparison was performed with filter sampling performed in parallel for $\mathrm{EC}, \mathrm{OC}$, and WSOC, providing further confidence on the results obtained by the online analyzers. A modified version of the aethalometer model was used to derive hourly concentrations of 3 organic aerosol (OA) sources: fossil fuel, wood burning, and secondary. This source apportionment was validated for primary OA (fossil fuel, wood burning) using time-resolved measurements of specific tracers (including levoglucosan, water-soluble potassium and methanol for wood burning) and showed that secondary organic aerosols (SOA) were the most abundant OA species during our study. Water-soluble properties of these different OA sources were investigated from the reconstruction of experimentally determined water-soluble/insoluble OC. About $23 \%$ of WSOC was found to be of a secondary (photochemical) origin. A large fraction of SOA was assigned as water-insoluble and could originate from semi-volatile primary OA from wood burning and/or anthropogenic emissions. These results have been obtained at a typical suburban site in France and may be then representative of a larger European area. They bring new light on the commonly accepted idea that SOA is mainly water-soluble.

Citation: Sciare, J., O. d'Argouges, R. Sarda-Estève, C. Gaimoz, C. Dolgorouky, N. Bonnaire, O. Favez, B. Bonsang, and V. Gros (2011), Large contribution of water-insoluble secondary organic aerosols in the region of Paris (France) during wintertime, J. Geophys. Res., 116, D22203, doi:10.1029/2011JD015756.

\section{Introduction}

[2] Fine anthropogenic aerosols (with aerodynamic diameter, A.D., below $2.5 \mu \mathrm{m}$ ) have been recognized as having strong but poorly understood adverse effects on health [Nel, 2005]; they may also have a significant climatic role on regional scales, inducing strong radiative forcing by directly scattering the sunlight and indirectly change cloud properties though the formation of cloud condensation nuclei [Ramanathan et al., 2007]. With half the world population living in cities, urban areas represent nowadays one of the major sources of fine anthropogenic aerosols on global scale, pointing out the need for a better characterization of these aerosols in the vicinity of their emission sources.

\footnotetext{
${ }^{1}$ Laboratoire des Sciences du Climat et de l'Environnement, CNRSCEA-UVSQ, Gif-sur-Yvette, France.

${ }^{2}$ Institut National de l'Environnement Industriel et des Risques, Verneuil-en-Halatte, France.

Copyright 2011 by the American Geophysical Union. 0148-0227/11/2011JD015756
}

[3] Organic aerosols (OA) make up a large fraction of fine aerosols but their sources are not well understood, especially the relative contributions of primary versus secondary organic aerosol. Primary organic aerosols (POA) are directly emitted by sources; secondary organic aerosols (SOA) are formed in the atmosphere from the oxidation products of gas phase precursors. Recent ambient measurements with Aerodyne Aerosol Mass Spectrometers (AMS) have shown that oxygenated OA (OOA) is the dominant component of OA in many anthropogenically influenced environments and could significantly contribute to SOA [Zhang et al., 2007]. In atmospheres which are not impacted by biomass burning, real-time measurements of watersoluble organic compounds (WSOC) performed using a Particle-Into-Liquid-Sampler coupled with a Total Organic Carbon (PILS-TOC) instrument have also shown to provide valuable information on SOA that could be mainly of biogenic origin [Sullivan et al., 2004, 2006; Heald et al., 2006; Miyazaki et al., 2006; Kondo et al., 2007; Weber et al., 2007; Hennigan et al., 2008a, 2008b]. Although these 2 techniques (AMS and PILS-TOC) can provide near real-time useful information on SOA, they still suffer from 
several limitations regarding, for instance, the origin of SOA (see for instance Grieshop et al. [2009a] for discussion on biomass burning SOA).

[4] Characterization of SOA in the urban atmosphere during the winter period appears therefore to be particularly difficult to assess especially in European cities due to the large use of wood burning for domestic heating which could contribute to $50-70 \%$ of the aerosol organic mass during winter [Gelencsér et al., 2007; Puxbaum et al., 2007; Lanz et al., 2010]. Low biogenic emissions during winter will also significantly reduce the amount of secondary watersoluble OA in the atmosphere making even more difficult the characterization of water-soluble SOA in urban atmospheres impacted by biomass burning. In this context, source apportionment of combustion and non-combustion OA sources is prerequisite for gaining more information on SOA origins and properties during winter.

[5] A source apportionment model (aethalometer model) has been developed recently by Sandradewi et al. [2008a] and optimized by Favez et al. [2010] in order to discriminate carbonaceous aerosols within 3 distinct sources; fossil fuel combustion source, biomass burning combustion source and a non-combustion source which can be assigned as SOA if we assume that primary OA sources (plants, spores, fungus) do not contribute significantly to OA levels in the fine mode. This model is based on the light absorbing properties of brown carbon which is assumed to refer to biomass burning aerosols [Hoffer et al., 2006; Lukács et al., 2007 and references therein]. Still very few studies have been using this model [e.g., Favez et al., 2009, 2010] which still needs to be better constrained by independent estimates of these 3 OA sources. Favez et al. [2010] have compared this model against two commonly used source apportionment models: Chemical Mass Balance (CMB, performed with off-line filter measurements) and Positive Matrix Factorization (PMF, applied to Aerosol Mass Spectrometer measurements). Significant discrepancies were obtained in the estimation of carbonaceous material from wood burning, pointing out possible inconstancies of $\mathrm{CMB}$ and $\mathrm{PMF}$ models. The aethalometer model also requires strong hypotheses, assuming for instance that biomass burning is the only source of brown-carbon containing particles. It may not be appropriate for a small (and stable) wood burning contribution as well as large and variable SOA sources since this model is based on regression analysis which requires significant changes in concentration levels of OA sources. Consequently, efforts are still required to further validate this aethalometer model against independent (tracer-based) estimates of combustion OA sources.

[6] An hourly resolved source apportionment of OA (fossil fuel, wood burning, and SOA) in the fine mode is performed here using an improved version of the aethalometer model for a 10-day period during the winter 2009 at a suburban site of Paris (France). Fossil fuel and wood burning $\mathrm{OA}$ derived from this model are tested against online and filter-based measurements of tracers for these 2 sources (water-soluble potassium, levoglucosan, methanol, $\mathrm{m}, \mathrm{p}$-xylenes). Water-soluble properties of the 3 OA sources (fossil fuel, wood burning and SOA) is then investigated from independent time-resolved measurements of watersoluble/insoluble organic carbon. A focus is made on SOA which is found to be mainly composed of water-insoluble organic material during the period of the study.

\section{Instrumentation}

\subsection{Sampling Site Description and Meteorology Overview}

[7] Atmospheric measurements were performed on the terraced roof ( $5 \mathrm{~m}$ above ground level) of the Laboratoire des Sciences du Climat et de l'Environnement (LSCE; $48^{\circ} 42^{\prime} 35.47^{\prime \prime} \mathrm{N}, 2^{\circ} 08^{\prime} 53.40^{\prime \prime} \mathrm{E}$ ). This site is located approximately $20 \mathrm{~km}$ southwest from the city of Paris and can be considered as a suburban atmospheric station. There is no direct pollution source in the vicinity of the station and the closest city (Gif/Yvette; 20,000 inhabitants) is located at about $3 \mathrm{~km}$ southward of the site. Results presented here were obtained for a 10-day period (12-21 February 2009). Meteorological parameters were monitored at the site every 5 min using a Campbell Scientific Weather Station. Temporal variations of air temperature $(\mathrm{T})$ and relative humidity $(\mathrm{RH})$ during the campaign are illustrated in Figure 1 and shows relatively cold weather (mean $\mathrm{T}$ of $3.7 \pm 2.9^{\circ} \mathrm{C}$ ) and very humid conditions (mean RH of $87 \pm 12 \%$ ).

\subsection{TEOM-FDMS}

[8] Reliable continuous (6-min time resolution) measurements of fine aerosol mass $\left(\mathrm{PM}_{2.5}\right)$ were performed during our study using a Tapered Element Oscillating Microbalance (TEOM) Model 1400 from Rupprecht \& Pataschnik equipped with a Sample Equilibration System (SES) and a Filter Dynamic Measurement System (FDMS, 8500 model series) [Grover et al., 2005; Sciare et al., 2007]. This instrument delivers a surrogate for concentration of semivolatile material (SVM), which is mainly made of ammonium nitrate for the Paris background atmosphere during winter [Favez et al., 2007]. The precision limits (given by the manufacturer) for TEOM measurements are $\pm 5.0 \mu \mathrm{g} / \mathrm{m}^{3}$ for 10 -min averaged data and $\pm 1.5 \mu \mathrm{g} / \mathrm{m}^{3}$ for 1 -h averages. A mean $\mathrm{PM}_{2.5}$ concentration of $24.8 \mu \mathrm{g} / \mathrm{m}^{3}$ was calculated for the period of study which is close to the yearly average of $\sim 20 \mu \mathrm{g} / \mathrm{m}^{3}$ calculated for the Paris urban background atmosphere using $\mathrm{PM}_{2.5}$ data from the local air quality network (AIRPARIF, http://www.airparif.asso.fr/).

\subsection{PILS-IC Instrument}

[9] Measurements of fine cations were performed using a Particle-into-Liquid-Sampler (PILS) [Orsini et al., 2003] running at 15LPM and coupled with an Ion Chromatograph (IC). Basic and acidic annular denuders (3-channel, URG Corp., USA) were mounted upstream of the PILS instrument and downstream of a sharp cut cyclone (model SCC2.229, BGI Inc., Whaltman, MA) having a 50\% cut-off diameter of $2.5 \mu \mathrm{m}$ at $16.67 \mathrm{LPM}$. Ambient concentrations of ions were corrected from blanks performed every day for $1 \mathrm{~h}$ and achieved by placing a total filter upstream of the sampling system. Liquid flow rates of the PILS were delivered by peristaltic pumps and set to $1.5 \mathrm{ml} / \mathrm{min}$ for producing steam inside the PILS and $0.5 \mathrm{ml} / \mathrm{min}$ for rinsing the impactor.

[10] Cation measurements were performed using an IC (Dionex, model ICS1500) equipped with a 2-mm diameter Auto-Suppression, Cation Self-Regenerating Suppressor 


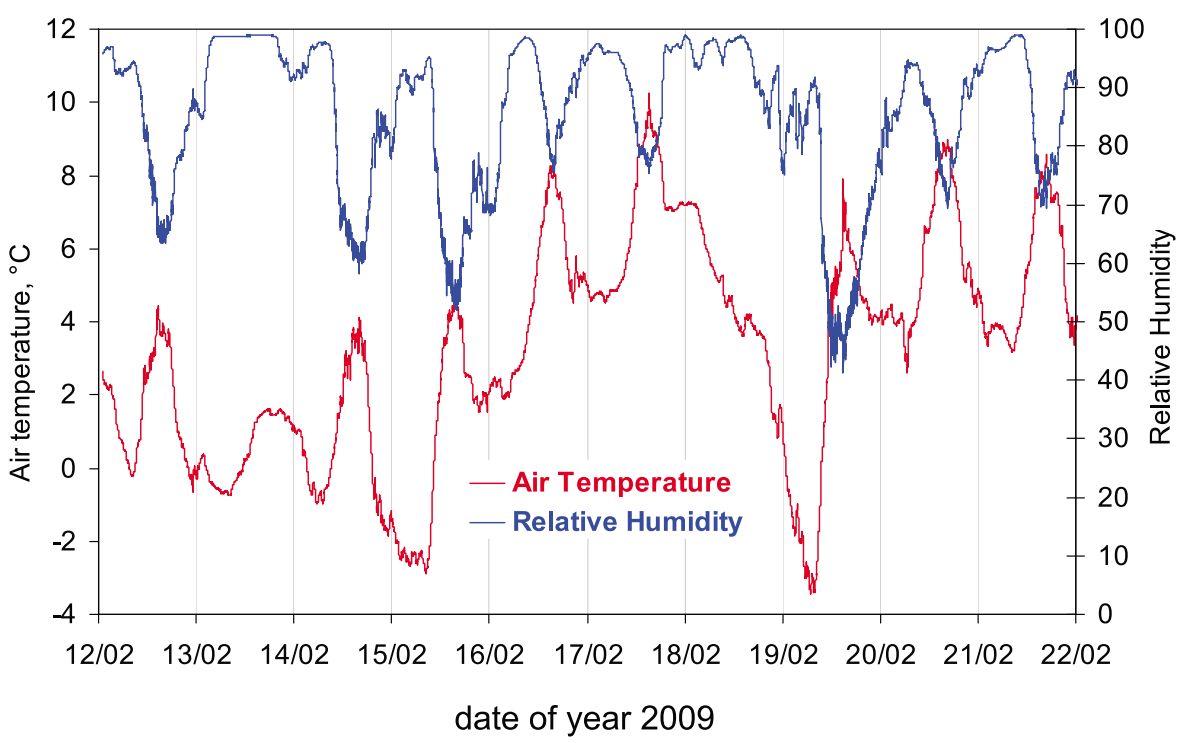

Figure 1. Air temperature and relative humidity during our study (12-22/02/2009).

(CSRS), a 2-mm diameter CS-12 pre-column and column, and a $100 \mu \mathrm{l}$ injection loop. Analyses were performed in isocratic mode at $20 \mathrm{mM}$ of Methanesulfonic Acid (MSA) at a flow rate of $0.25 \mathrm{ml} / \mathrm{min}$, for the quantitative determination of the 5 major cations $\left(\mathrm{Na}^{+}, \mathrm{NH}_{4}^{+}, \mathrm{K}^{+}, \mathrm{Mg}^{2+}, \mathrm{Ca}^{2+}\right)$ every $10 \mathrm{~min}$. Based on these IC settings, the detection limit $(2 \sigma)$ for cations was typically $0.1 \mathrm{ppb}$, which corresponds to an atmospheric concentration of $\sim 1 \mathrm{ng} / \mathrm{m}^{3}$. Calibration was performed for concentrations ranging from 1 to $100 \mathrm{ppb}$ and showed a drift below $5 \%$ between the beginning and the end of the campaign.

\subsection{PILS-TOC Instrument}

[11] Measurements of WSOC were performed every $4 \mathrm{~min}$ using a modified Particle-into-Liquid-Sampler (Brechtel Manufacturing Inc., USA) [Sorooshian et al., 2006] coupled with a total organic carbon analyzer (TOC, Model Sievers 900, Ionics Ltd, USA). A activated carbon parallel plate denuder [Eatough et al., 1993] (similar to those operating in the OCEC Sunset field instrument and for filter sampling) was mounted upstream of the PILS instrument to minimize the influence of volatile organic compounds (VOC) on our WSOC measurements. A sharp cut cyclone (BGI Inc., Whaltman, MA) was mounted upstream of the VOC denuder in order to collected fine aerosols $(50 \%$ cut-off diameter of $2.5 \mu \mathrm{m}$ at $16.67 \mathrm{LPM})$. The PILS-TOC instrument was running at 15LPM and a constant dilution factor of 1.25 was taken in the instrument which is close to the one reported by Sullivan et al. [2006]. Liquid flow rates of the PILS were delivered by syringe pumps and set to $1.5 \mathrm{ml} / \mathrm{min}$ for producing steam inside the PILS and $0.7 \mathrm{ml} / \mathrm{min}$ for rinsing the impactor. A polyethylene filter of $0.45 \mu \mathrm{m}$ pore size diameter was set in-line in the aerosol liquid flow (downstream of the PILS collector) in order to analyze solely the watersoluble OC fraction. The collection efficiency of insoluble carbonaceous particles on the filter was checked by mounting a second in-line polyethylene filter (of $0.2 \mu \mathrm{m}$ pore size diameter) behind it. No significant variations in WSOC concentrations were observed using this set-up and a black deposit (i.e., soot particles) was only observed on the first in-line filter of $0.45 \mu \mathrm{m}$ pore size diameter. This result is consistent with the poor capability of the PILS to collect insoluble carbonaceous material [Peltier et al., 2007]. Ultrapure water (mQ grade) with trace concentrations of TOC from an ELGA Maxima Ultra Pure Water Unit was used here for the PILS-TOC instrument. Similar to the PILS-IC measurements, daily blanks for the PILS-TOC instrument were achieved by placing a total filter upstream of the sampling system for $1 \mathrm{~h}$. In this configuration, approximately 15 min were necessary to reach blank values which were very stable during the campaign showing a mean concentration of $31.4 \pm 2.7 \mathrm{ppbC}$. Note that most of the blank concentration refers to the TOC concentration in the ultra-pure water used in the PILS instrument (typically $25 \mathrm{ppbC}$ ), suggesting little contamination in the PILS instrument as well as a good efficiency of the VOC denuder placed upstream. Note also that the daily blanks for the PILS-TOC instrument were performed at different hours of the day and did not show a clear diurnal pattern that could be linked to diurnal variations of VOC. Ambient WSOC measurements were then corrected from this blank value. Limit of quantification of ambient WSOC measurements was estimated as twice the uncertainty calculated for the blank concentrations, corresponding to about $0.36 \mu \mathrm{gC} / \mathrm{m}^{3}$. A maximum uncertainty of $10 \%$ is calculated here which is comparable to the 5-10\% uncertainty reported for PILSTOC measurements [Sullivan et al., 2004, 2006]. A total of 2852 valid data points were collected for the period of the study, corresponding to a mean ambient (blank corrected) WSOC concentration of $31.6 \pm 21.3$ ppbC (i.e., $2.10 \pm$ $\left.1.46 \mu \mathrm{gC} / \mathrm{m}^{3}\right)$. Temporal variations of $4-\mathrm{min}$ resolved WSOC concentrations are reported in Figure 2a. In the following, hourly data of water-insoluble organic carbon (WIOC) were obtained from the difference between OC data given by the OCEC Sunset field instrument and WSOC data given by the PILS-TOC. Conversion factors of 1.3 and 2.1 were taken to convert WIOC into WIOM (water-insoluble organic matter) and WSOC into WSOM (water-soluble 


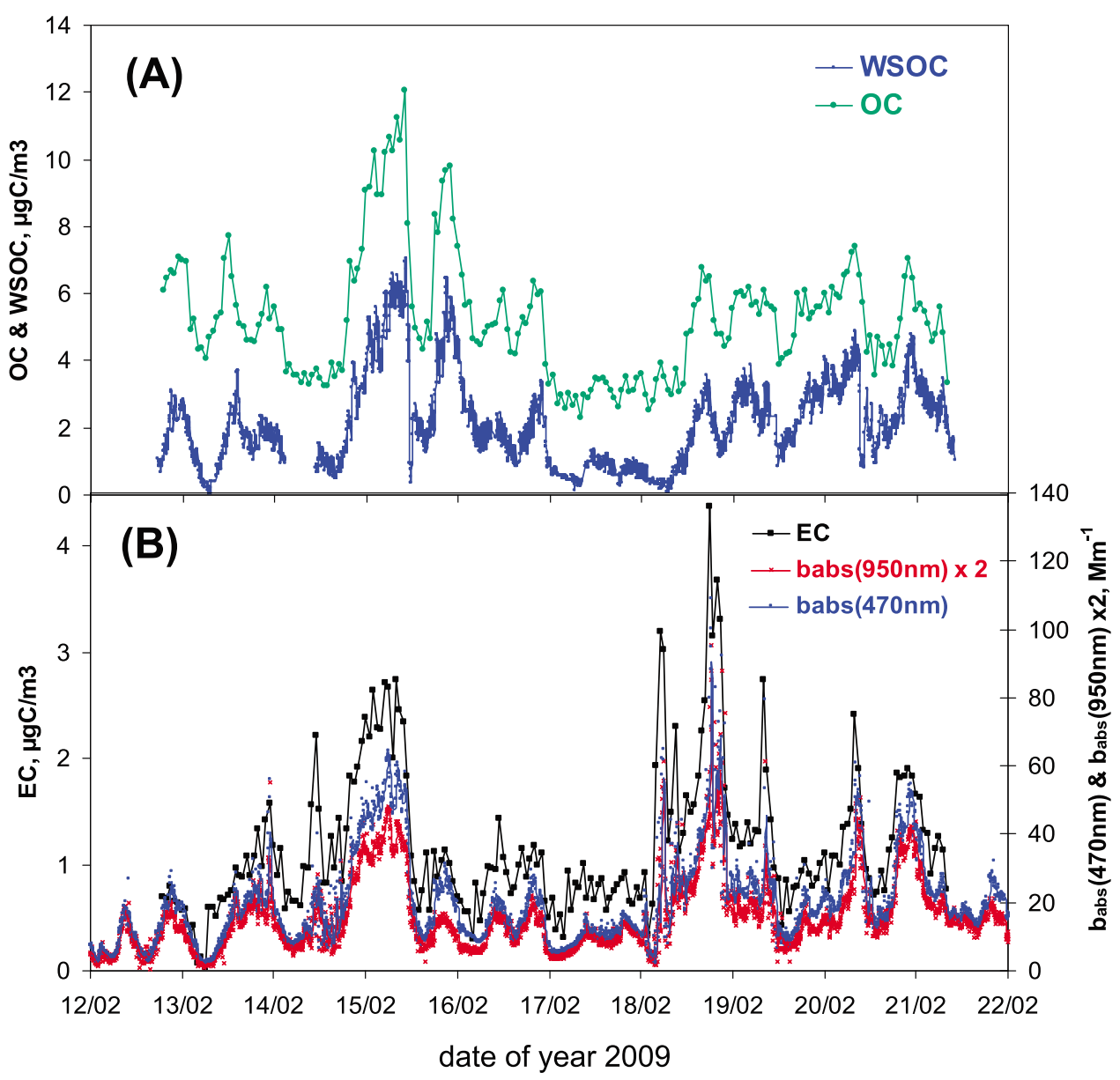

Figure 2. Temporal variations of (a) semi-continuous hourly OC concentrations (from the OCEC Sunset $\mathrm{Lab}$ instrument) and 4-min WSOC concentrations (from the PILS-TOC instrument). (b) Semi-continuous hourly EC concentrations (from the OCEC Sunset Lab instrument) and 5-min light absorption coefficient $\left(b_{a b s}\right)$ at 470 and $950 \mathrm{~nm}$ (from the 7- $\lambda$ aethalometer instrument).

organic matter) [Turpin and Lim, 2001; Zhang et al., 2005]. Note that the relative contribution of the different (primary and secondary) OA sources contributing to WSOC may be highly variable from one location to another and should also present significant temporality [Decesari et al., 2001; Sullivan and Weber, 2006a, 2006b]. The amount of oxygenated compounds in WSOC may then change considerably, leading to quite different organic mass to organic carbon mass ratios [Kiss et al., 2002]. For that reason, significant uncertainties may lie in the choice of proper and constant conversion factor for WSOC. Sensitivity studies have been performed for that purpose in order to evaluate the impact of our hypotheses on organic mass to organic carbon mass ratios on our OA source apportionment results. They are presented and discussed in section 4.3.

\subsection{Filter Sampling and Chemical Analyses}

[12] Fine aerosols were collected every $6 \mathrm{~h}$ on $47-\mathrm{mm}$ diameter pre-fired quartz filters (QMA, Whatman) using a Partisol Plus sampler (model 2025, Thermo Scientific, USA) equipped with a $\mathrm{PM}_{2.5}$ sharp cut cyclone running at 16.67LPM (model SCC2.229, BGI Inc., Whaltman, MA). A VOC denuder identical to the one used upstream of the
OCEC Sunset field instrument and the PILS-TOC was set between the cyclone and the Partisol Plus sampler.

\subsubsection{Determination of EC, OC, and WSOC}

[13] A total of 31 continuous samples were collected for the period 13-21/02. Punches of $1.5 \mathrm{~cm}^{2}$ were taken from each filter and analyzed for EC and OC content using a thermo-optical carbon analyzer (OCEC Sunset Lab Instrument; Sunset Laboratory, Forest Groove, OR, USA) implemented with the NIOSH thermal program [Birch and Cary, 1996]. The uncertainty given by the manufacturer for $\mathrm{EC}$ and $\mathrm{OC}$ measurements is $0.2 \mu \mathrm{gC} / \mathrm{cm}^{2} \pm 5 \%$. A total of 7 blanks were taken in the field covering the duration of the campaign and showed non-detectable amounts of EC. A mean $\mathrm{OC}$ value of $0.20 \pm 0.10 \mu \mathrm{gC} / \mathrm{cm}^{2}$ was calculated here for blank filters and corresponded to about $5 \%$ of OC concentrations measured in the field. These blanks were then subtracted from the ambient $\mathrm{OC}$ values.

[14] Water-soluble organic carbon (WSOC) analyses were achieved on a second punch of $1.5 \mathrm{~cm}^{2}$ taken on 21 consecutive quartz filters covering the period 13-19/02. WSOC measurements were performed using a total organic carbon analyzer (TOC, Model Sievers 900, Ionics Ltd, USA) in which ammonium persulphate and UV light (185 and 
$284 \mathrm{~nm}$ ) are used for the chemical oxidation of WSOC into $\mathrm{CO}_{2}$ further detected by conductivity. Information on filter extraction protocol, detection limit, and calibration for WSOC analysis is provided by Sciare et al. [2009]. Ambient concentrations of WSOC were ranging from 237.0 to $1403.3 \mathrm{ppbC}(630.7 \pm 275.8 \mathrm{ppbC}$ on average). These concentrations were corrected using the blank filters taken in the field with blanks showing an average WSOC concentration of $83.6 \pm 9.1 \mathrm{ppbC}$ (corresponding to $0.46 \pm$ $\left.0.05 \mu \mathrm{gC} / \mathrm{m}^{3}\right)$. An uncertainty of $10 \%$ is estimated here for the analytical determination of WSOC from the filters.

\subsubsection{Determination of Levoglucosan}

[15] Monosaccharides and sugar alcohols (incl. levoglucosan, mannitol, arabitol) have been determined following the technique reported by Iinuma et al. [2009], using an ion chromatograph (DIONEX, model ICS 3000) system equipped with an electrochemical detector and gold electrode. The separation is performed using a Dionex CarboPac MA1 4-mm diameter column. Eluant type, concentrations, and gradients are similar to those reported by Iinuma et al. [2009]. Punches of $1.5 \mathrm{~cm}^{2}$ of each QMA filter sampled with the Partisol Plus sampler (see above) were placed into rinsed plastic vials containing $5 \mathrm{ml}$ of $\mathrm{mQ}$ water, and were extracted by sonication for $40 \mathrm{~min}$. Extracted liquid samples were immediately filtered $(0.45 \mu \mathrm{m}$ pore size diameter polyethylene filter) and analyzed for 11 sugar alcohols, monosaccharides, and monosaccharide anhydrides (including levoglucosan, mannosan, and galactosan). Linear calibration (with $\mathrm{r}^{2}$ better than 0.99) was obtained for all these compounds with standard concentrations ranging $10 \mathrm{ppb}$ to $1 \mathrm{ppm}$ allowing the quantification of levoglucosan at pbb levels. Limit of quantification for levoglucosan was about $5 \mathrm{pbb}$ which is similar to the one reported by Iinuma et al. [2009]. Based on our sampling settings (6 h sampling at $1 \mathrm{~m}^{3} / \mathrm{h}$ and $1.5 \mathrm{~cm}^{2}$ of sampled filter extracted in $5 \mathrm{ml}$ ), this limit corresponds to an atmospheric concentration of levoglucosan of about $35 \mathrm{ng} / \mathrm{m}^{3}$. Blank filters collected in the field did not show detectable amounts of levoglucosan. A total of 31 filter samples were analyzed and showed detectable amounts of levoglucosan with concentrations ranging from 10 to $127 \mathrm{ppb}$ (average of $39.7 \pm 30 \mathrm{ppb}$ ) corresponding to ambient concentrations ranging from 72 to $919 \mathrm{ng} / \mathrm{m}^{3}$ (average of $285 \pm 223 \mathrm{ng} / \mathrm{m}^{3}$ ).

\subsection{OCEC Sunset Field Instrument}

[16] Semi-continuous hourly concentrations of elemental carbon (EC) and organic carbon (OC) in $\mathrm{PM}_{2.5}$ were obtained in the field from an OCEC Sunset field instrument (Sunset Laboratory, Forest Grove, OR, USA; Bae et al. [2004]) running at 8LPM. A denuder provided by the manufacturer was set upstream in order to remove possible adsorption of VOCs onto the filter used to collect fine aerosols in the instrument. Measurement uncertainty given by the OCEC Sunset field instrument is poorly described in literature and an estimate of $20 \%$ for this uncertainty was taken here following Peltier et al. [2007]. A total of 206 valid $\mathrm{EC}$ and $\mathrm{OC}$ data points were collected for the period (12-21/02/2009) and reported in Figure 2.

\subsection{Aethalometer}

[17] Aerosol absorption coefficients $\left(b_{a b s}\right)$ were obtained every $5 \mathrm{~min}$ at seven different wavelengths $(370,470,520$,
$590,660,880$ and $950 \mathrm{~nm})$ using a Magee Scientific aethalometer (model AE-31) equipped with a cyclone having a $50 \%$ cut-off diameter of $2.5 \mu \mathrm{m}$ (R\&P, Albany, NY). This instrument was operating at a flow rate of 5LPM in an automated mode, under which the filter tape advances when the attenuation (ATN) at $370 \mathrm{~nm}$ reaches 100. Due to the methodology used within the aethalometer (filter-based measurements), absorption coefficients directly obtained from this instrument are affected by various sampling and analytical artifacts (mostly referred to as multiple scattering and shadowing effects) which need to be carefully corrected for [Collaud Coen et al., 2010, and references therein]. In the present work, we have processed the data following the same procedures reported by Favez et al. [2010]. The correction procedure introduced by Weingartner et al. [2003] was applied to our data set as follows:

$$
\mathrm{b}_{\mathrm{abs}, \lambda, \mathrm{t}}=\mathrm{b}_{\mathrm{aeth}, \lambda, \mathrm{t}} /\left(2.14 \times \mathrm{R}(\mathrm{ATN})_{\lambda, \mathrm{t}}\right)
$$

Where, at a given time (t) and a given wavelength $(\lambda), \mathrm{b}_{\mathrm{abs}, \lambda, \mathrm{t}}$ and $b_{\text {aeth }, \lambda, t}$ stand for the corrected absorption coefficient and the raw absorption coefficient, respectively. The constant (2.14) stands for multiple scattering of the light beam by the filter fibers in the unloaded filter. Finally, $\mathrm{R}(\mathrm{ATN})_{\lambda, \mathrm{t}}$ describes the decrease of the latter artifact with the gradual accumulation of soot particles on/in the filter (i.e., correction of the shadowing effect). $\mathrm{R}(\mathrm{ATN})_{\lambda, \mathrm{t}}$ was determined following the equation:

$$
\mathrm{R}(\mathrm{ATN})_{\lambda, \mathrm{t}}=\left(\frac{1}{f_{\lambda}}-1\right) \times \frac{\ln \left(\mathrm{ATN}_{\lambda, \mathrm{t}}\right)-\ln (10)}{\ln (50)-\ln (10)}+1
$$

where $\operatorname{ATN}_{\lambda, t}$ corresponds to the light attenuation measured by the aethalometer at a given time $(\mathrm{t})$ and a given wavelength $(\lambda)$, and $f_{\lambda}$ allows for the correction of the instrumental error that occurs when the shadowing effect is disregarded. The latter parameter was determined here by keeping the median ratio of absorption coefficients (before and after the change of each filter spot) the closest to 1 . The overall uncertainty of absorption coefficients calculated this way is on the order of $20 \%$. Nevertheless, this uncertainty is expected to affect measurements at each wavelength in a relatively similar way, so that a higher confidence level is assumed for the spectral shape of light absorption. Note also that the $b_{a b s}$ corrections applied here [from Weingartner et al., 2003] stand for the best corrections in the absence of light scattering coefficient measurements [Collaud Coen et al., 2010].

[18] Temporal variations of 5-min integrated $b_{a b s}$ at 470 and $950 \mathrm{~nm}$ are compared in Figure $2 \mathrm{~b}$ with the EC obtained on an hourly basis by the OCEC Sunset field instrument.

\subsection{Automatic GC-FID}

[19] Non-methane hydrocarbons (NMHC) in ambient air were measured using two portable gas chromatographs equipped with a flame ionization detector (GC-FID, Chromatotec, France). The first analyzer, ChromaTrap, allowed the measurement of $\mathrm{C}_{2}-\mathrm{C}_{6}$ hydrocarbons and the second, AirmoBTX, the measurement of $\mathrm{C}_{6}-\mathrm{C}_{10}$ hydrocarbons.

[20] Briefly, for each sample, $180 \mathrm{~mL}$ for ChromaTrap and $660 \mathrm{~mL}$ for AirmoBTX of air was drawn through a $1 / 8 \mathrm{inch}$ 
diameter $6 \mathrm{~m}$-long stainless steel line with a flow rate of $18 \mathrm{~mL} / \mathrm{min}$ for ChromaTrap and $60 \mathrm{~mL} / \mathrm{min}$ for AirmoBTX. First, for the ChromaTrap instrument, ambient air was passed through a Nafion dryer to reduce the water content. Then hydrocarbons were preconcentrated for ChromaTrap at $-8^{\circ} \mathrm{C}$ on a glass trap containing adsorbents Carboxen 1000/ Carbopack B/Carbotrap C and for AirmoBTX at ambient temperature on a glass trap containing the adsorbent Carbotrap $\mathrm{C}$. Then the trap was heated rapidly to $220^{\circ} \mathrm{C}$ for $3 \mathrm{~min}$ for ChromaTrap and to $380^{\circ} \mathrm{C}$ over $2 \mathrm{~min}$ for AirmoBTX, to desorb the preconcentrated VOC into a separating column (Plot Column $\mathrm{Al}_{2} \mathrm{O}_{3} / \mathrm{Na}_{2} \mathrm{SO}_{4}, 25 \mathrm{~m} \times 0.53 \mathrm{~mm}$ diameter for ChromaTrap and MXT30CE, $30 \mathrm{~m} \times 0.28 \mathrm{~mm}$ diameter for AirmoBTX). For both instruments, the sampling time was $10 \mathrm{~min}$ and analysis time was $20 \mathrm{~min}$ and, therefore, measurements were performed with a time resolution of $30 \mathrm{~min}$. During the campaign, a certified calibrated gas bottle (from National Physics Laboratory) containing thirty non-methane hydrocarbons at 4-5 ppb level was injected several times. These series of measurements allowed the confirmation of compound retention times and the calculation of one average response factor per instrument which was used to calibrate measurements from the campaign.

[21] Tests performed in the laboratory have shown a repeatability of the measurement better than $5 \%$ for almost all compounds and an overall uncertainty better than $15 \%$. More technical information (including performance of this instrument) is provided by Bonsang et al. [2008] and Gros et al. [2011].

\subsection{PTR-MS}

[22] During the campaign, a new high sensitivity Proton Transfer Mass Spectrometer (PTR-MS from Ionicon Analytik, Austria) was used to monitor selected VOCs which were not measured by the GC-FIDs. The PTR-MS technology was first introduced in the atmospheric chemistry community by Lindinger et al. [1998] and has been extensively described in the literature [Blake et al., 2009; de Gouw and Warneke, 2007, and references therein]. Briefly, compounds $(\mathrm{R})$ having a proton affinity larger than water react within a flow drift tube with $\mathrm{H}_{3} \mathrm{O}^{+}$according to the reaction $\left(\mathrm{R}+\mathrm{H}_{3} \mathrm{O}^{+} \rightarrow \mathrm{RH}^{+}+\mathrm{H}_{2} \mathrm{O}\right)$, are then selected by a quadrupole mass spectrometer and detected by a second electron multiplier. The measured mass $(\mathrm{mz})$ corresponds to the molecular mass +1 which may correspond to several compounds. For this specific campaign, a focus was made on selected masses which can be attributed to the following compounds $\mathrm{m} 33$ (methanol), $\mathrm{m} 42$ (acetonitrile), m45 (acetaldehyde), m59 (acetone) [de Gouw and Warneke, 2007].

[23] Measurement conditions during the campaign were 15 to 20 millions of primary ions $\left(\mathrm{H}_{3} \mathrm{O}^{+}\right)$, a pressure of 2.24 mbar into the reaction chamber and a drift field maintained at $600 \mathrm{~V} / \mathrm{cm}$. Air was sampled through a 5-m Teflon line (1/16" inner diameter) heated at $60^{\circ} \mathrm{C}$ with a flow rate of about $75 \mathrm{ml} / \mathrm{min}$. Time resolution of the measurements was every $30 \mathrm{~s}$, with an integration time of $1 \mathrm{~s}$ for each $\mathrm{mz}$ (about 30 masses were monitored, but only four were selected for the present study).

[24] The instrumental background was determined by switching incoming air over a catalytic converter Platinum coated wool heated to $350^{\circ} \mathrm{C}$ during $5 \mathrm{~min}$ every $15 \mathrm{~min}$. The background signals obtained for each measured mass were averaged and subtracted from the atmospheric signals. The background levels of the compounds considered here were $62.8 \pm 1.9,0.4 \pm 0.2,16.6 \pm 0.3$ and $2.8 \pm 0.0$ normalized counts per second (ncps) for methanol, acetonitrile, acetaldehyde and acetone, respectively.

[25] The primary reagent count varied between 15 to 20 millions counts. After normalization to 1 million primary ions the instrument sensitivity was between 5 (methanol) and $18 \mathrm{ncps} / \mathrm{ppbv}$ (acetonitrile and acetone). The instrument was calibrated at the Max Planck Institute for chemistry (Mainz, Germany), using a gas standard bottle (Apel-Riemer Environmental Inc.) containing about $500 \mathrm{ppb}$ of each measured compound and injected at different amounts by dilution with synthetic air. Details about this standard is provided by Gros et al. [2011]. As the response of the PTRMS is directly influenced by the humidity rate of the analyzed sample, calibrations with diverse humidity rates were performed. For the present data, the $80 \%$ humidity rate calibration was taken into consideration, as the ambient relative humidity varied in-between 65 and 95\% during the campaign.

\section{The Aethalometer Model}

[26] The source apportionment performed by the aethalometer model [Sandradewi et al., 2008a] is based on the strong spectral dependence of light absorption properties of brown carbon aerosols [Hoffer et al., 2006 and references therein], and the use of a multiwavelength aethalometer to detect the presence of this brown carbon fraction in ambient biomass burning aerosols [e.g., Jeong et al., 2008; Sandradewi et al., 2008b; Yang et al., 2009]. In the present study, the large contribution of brown carbon aerosols on the spectral dependence of light absorption properties could be observed as illustrated in Figure 3 by the temporal variation of the angstrom exponent $\left(\alpha_{470-950}\right)$ calculated between the 2 wavelengths of the aethalometer $(470$ and $950 \mathrm{~nm})$. As shown by this Figure, large changes in the spectral dependence of the light absorption were observed with higher contribution of brown carbon aerosols (i.e., higher $\alpha$ values) at night.

[27] Recent studies have shown that information delivered by a multiwavelength aethalometer could be used in a more quantitative way - in conjunction with complementary carbon measurements - to provide a source apportionment of biomass burning aerosols in the context of an atmospheric mixture of carbonaceous aerosols having both modern (biomass burning) and fossil fuel origins [Sandradewi et al., 2008a; Favez et al., 2009, 2010]. This aethalometer model has been applied to our data sets. Details of this model are given below.

[28] Total carbonaceous material $\left(\mathrm{CM}_{\text {total }}\right)$ is primarily considered as the sum of brown-carbon-containing carbonaceous material originating from wood burning (noted as $\mathrm{CM}_{\mathrm{wb}}$ ), non brown-carbon-containing carbonaceous material originating from fossil fuel combustion (noted as $\mathrm{CM}_{\mathrm{ff}}$ ), and non-combustion OA (noted as $\mathrm{OM}_{\text {residual }}$ ). Note that the assumption made here that wood burning is the main contributor of UV-absorbing brown carbon during the cold months has been recently verified by Hecobian et al. [2010] who have performed a year-round record of light absorption spectra of fine WSOC. Note also that such an assumption is 


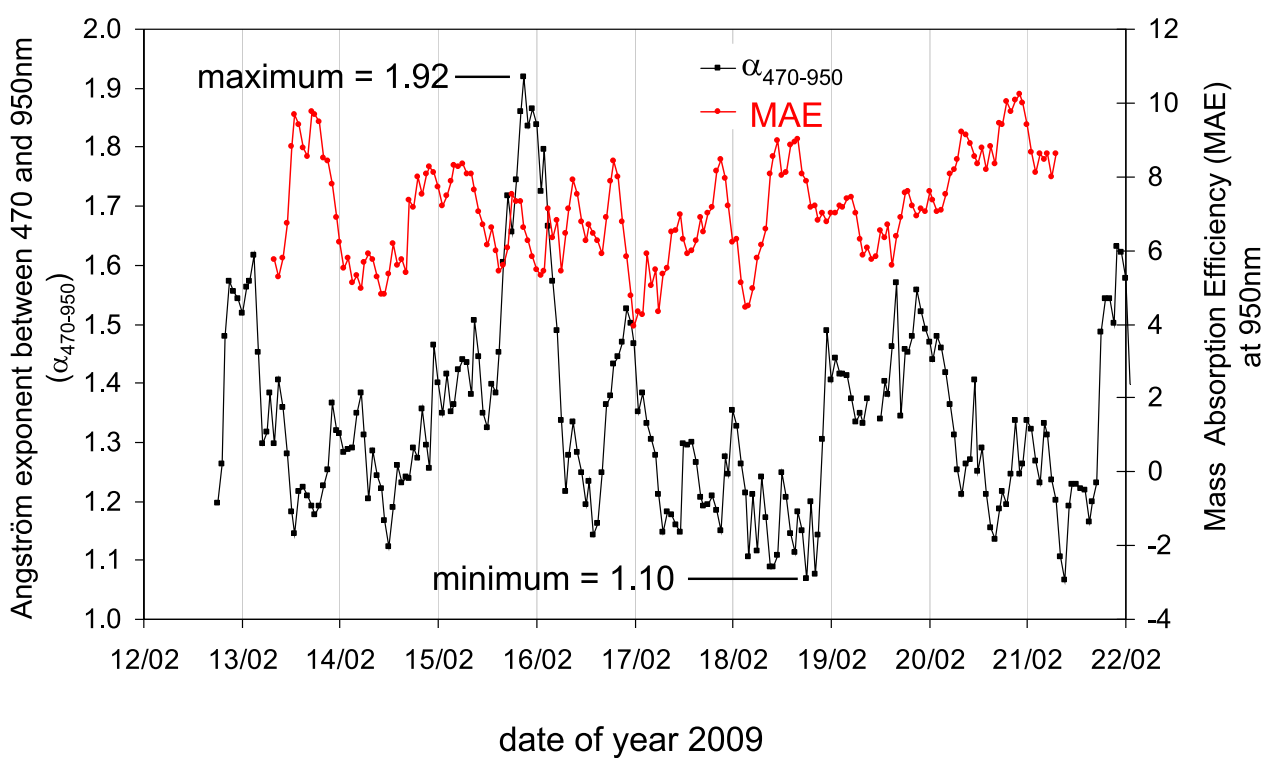

Figure 3. Temporal variations of the angstrom exponent between 470 and $950 \mathrm{~nm}\left(\alpha_{470-950}\right)$ obtained from the 7- $\lambda$ aethalometer instrument and the Mass Absorption Efficiency (MAE) calculated as the ratio between EC (OCEC Sunset Lab instrument) and $b_{a b s}$ at $950 \mathrm{~nm}$ (7- $\lambda$ aethalometer instrument). Minimum and maximum of $\left(\alpha_{470-950}\right)$ are noted here and stand for the highest contribution to the light absorption properties of fossil fuel and wood burning combustion sources, respectively.

valid only if we assume a weak influence of dust aerosols which have shown to contribute also to the absorbance in the UV range [Fialho et al., 2005].

[29] Non combustion OA $\left(\mathrm{OM}_{\text {residual }}\right)$ comprises both primary biogenic organic aerosols (PBOA) (plants, pollen, spores ...) and secondary organic aerosols (SOA). Based on the fact most of the particulate mass of primary biogenic aerosols is located in supermicron aerosols [Bauer et al., 2008a, and references therein], it can be reasonably assumed here that biogenic POA do not contribute significantly to $\mathrm{OM}_{\text {residual }}$ in our fine aerosol fraction. Note that estimates of biogenic POA can be performed here using arabitol and mannitol as tracers of fungal spore emissions (i.e., primary biological aerosol particles [Bauer et al., $2008 \mathrm{~b}]$ ). Non detectable amounts of arabitol and mannitol $\left(<35 \mathrm{ng} / \mathrm{m}^{3}\right)$ were obtained in the filter samples collected during our study. Using the emission factors of arabitol and mannitol per fungal spore reported by Bauer et al. [2008b] and an OC content of $5.2 \mathrm{pg} / \mathrm{spore}$ proposed by Bauer et al. [2002] for $\mathrm{PM}_{10}$ samples, a raw estimate of maximum $0.15 \mu \mathrm{gC} / \mathrm{m}^{3}$ can be calculated here for PBOA. This is about 35 times lower compared to our mean value of $5.36 \pm$ $1.33 \mu \mathrm{g} / \mathrm{m}^{3}$ calculated for $\mathrm{OM}_{\text {residual. }}$. For that reason, it can be reasonably assume that our $\mathrm{OM}_{\text {residual }}$ refers mainly to SOA. This is also supported by recent results obtained by Gilardoni et al. [2011] who have shown PBOA concentrations below $0.1 \mu \mathrm{g} / \mathrm{m}^{3}$ for the entire year in fine aerosols at a European background site.

[30] Based on these different observations, carbonaceous material can then be decomposed as:

$$
\begin{aligned}
\mathrm{CM}_{\text {total }}= & \mathrm{CM}_{\mathrm{ff}}+\mathrm{CM}_{\mathrm{wb}}+\mathrm{OM}_{\text {residual }}=\mathrm{C}_{1} \times \mathrm{b}_{\mathrm{abs}, \mathrm{ff}, 950 \mathrm{~nm}} \\
& +\mathrm{C}_{2} \times \mathrm{b}_{\mathrm{abs}, \mathrm{wb}, 470 \mathrm{~nm}}+\mathrm{C}_{3}
\end{aligned}
$$

where $b_{\text {abs,ff,950nm }}$ stands for the absorption coefficient of $\mathrm{CM}_{\mathrm{ff}}$ at $950 \mathrm{~nm}, \mathrm{~b}_{\mathrm{abs}, \mathrm{wb}, 470 \mathrm{~nm}}$ for the absorption coefficient of $\mathrm{CM}_{\mathrm{wb}}$ at $470 \mathrm{~nm}, \mathrm{C}_{1}$ and $\mathrm{C}_{2}$ for the light absorption to the particulate mass of both sources, and $\mathrm{C}_{3}$ corresponds to the amount of non-combustion $\mathrm{OA}\left(\mathrm{OM}_{\text {residual }}\right)$. It should be noted that fossil fuel carbonaceous material $\left(\mathrm{CM}_{\mathrm{ff}}\right)$ comprises traffic emissions as well as carbonaceous aerosols originating from domestic heating using fuel oil and natural gas combustion. It should also be mentioned that in the aethalometer model, $\mathrm{CM}_{\mathrm{ff}}$ and $\mathrm{CM}_{\mathrm{wb}}$ may contain a fraction of secondary material (or oxidized primary organic aerosols) that have been condensed on primary combustion particles of fossil fuel and wood burning origin. For that reason, it may be appropriate to consider $\mathrm{OM}_{\text {residual }}$ as the fraction of SOA that has not rapidly condensed onto primary combustion CM. Equation (3) can be solved when combined with the following ones:

$$
\begin{aligned}
& \mathrm{CM}_{\text {total }}=\mathrm{EC}+\mathrm{OM} \\
& \mathrm{b}_{\mathrm{abs}, \lambda}=\mathrm{b}_{\mathrm{abs}, \mathrm{ff}, \lambda}+\mathrm{b}_{\mathrm{abs}, \mathrm{wb}, \lambda} \\
& \left(b_{\text {abs, ff }, 470 \mathrm{~nm}} / \mathrm{b}_{\mathrm{abs}, \mathrm{ff}, 950 \mathrm{~nm}}\right)=(470 / 950)^{-\alpha \mathrm{ff}} . \\
& \left(b_{\mathrm{abs}, w b, 470 \mathrm{~nm}} / \mathrm{b}_{\mathrm{abs}, \mathrm{wb}, 950 \mathrm{~nm}}\right)=(470 / 950)^{-\alpha \mathrm{wb}} .
\end{aligned}
$$

EC and OM data in equation (4) are obtained from the OCEC Sunset field instrument and a conversion factor for OC-OM of 1.80. In equations (6) and (7), $\alpha_{\mathrm{ff}}$ and $\alpha_{\mathrm{wb}}$ stand for the Angstrom absorption exponents of fossil fuel and 
wood burning, respectively. In this study, a $\alpha_{\mathrm{ff}}$ value of 1.1 was taken, corresponding to the mean $\alpha$ value obtained for the lowest OC/EC ratios observed during our study (afternoon traffic peak on the $18 / 02$, Figure 3 ). This value is similar to the ones used in the previous studies using the aethalometer model (see for instance Favez et al. [2010]). A $\alpha_{\mathrm{wb}}$ value of 2.0 was taken here, based on values previously reported for wood burning aerosols [e.g., Clarke et al., 2007; Lewis et al., 2008] and used by Favez et al. [2010]. This value is also close to our highest $\alpha$ value of 1.92 obtained on 15/02 at 22:00 LT (Figure 3).

[31] In order to properly assign the contribution of fossil fuel $\left(\mathrm{CM}_{\mathrm{ff}}\right)$ and wood burning $\left(\mathrm{CM}_{\mathrm{wb}}\right)$ to $\mathrm{BC}\left(\mathrm{BC}_{\mathrm{ff}}\right.$ and $\left.\mathrm{BC}_{\mathrm{wb}}\right)$ and to $\mathrm{OM}\left(\mathrm{OM}_{\mathrm{ff}}, \mathrm{OM}_{\mathrm{wb}}\right.$ and $\left.\mathrm{OM}_{\text {residual }}\right)$, we first calculated $\mathrm{BC}$ mass concentrations from absorption measurements provided by the aethalometer instrument using a specific Mass Absorption Efficiency (MAE) calculated from

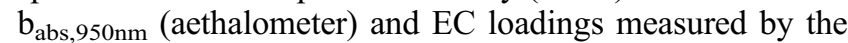
OCEC Sunset field instrument. A mean MAE value of $7.3 \pm$ $0.1 \mathrm{~m}^{2} / \mathrm{g}$ was obtained from this linear regression $\left(\mathrm{r}^{2}=0.85\right.$, $\mathrm{N}=206$ ) and was used here to estimate $\mathrm{BC}$ concentrations every $5 \mathrm{~min}$ from the $b_{\mathrm{abs}, 950 \mathrm{~nm}}$ data set. This MAE value is significantly higher than that recommended by Bond and Bergstrom [2006] at this wavelength for fresh soot $(\sim 4.3 \pm$ $0.6 \mathrm{~m}^{2} / \mathrm{g}$ ). This could be attributed to a possible encapsulation of soot particles by organic/inorganic compounds leading to an increase of MAE [Liousse et al., 1993; Bond and Bergstrom, 2006; Lack et al., 2008]. Alternatively, the use of the NIOSH protocol in the OCEC Sunset field instrument for biomass burning aerosols may lead to an underestimation of EC concentrations that could explain our high MAE [Sciare et al., 2003].

[32] In order to calculate $\mathrm{BC}_{\mathrm{ff}}$ and $\mathrm{BC}_{\mathrm{wb}}$ from $\mathrm{BC}$ concentrations, an assumption was made of an equivalent $\mathrm{MAE}$ for these 2 sources. In order to test the consistency of this assumption we have reported in Figure 3, together with $\alpha_{470-950}$, the temporal variations of MAE defined as the ratio between $b_{a b s, 950 \mathrm{~nm}}$ and EC. Although the MAE has shown to vary substantially from 4 to $10 \mathrm{~m}^{2} / \mathrm{g}$, no clear relationship $\left(r^{2}=0.05\right)$ could be define between MAE and the relative contribution of wood burning depicted here by the angstrom exponent $\left(\alpha_{470-950}\right)$. The lack of correspondence between these 2 data sets may suggest that other processes (such as encapsulation of soot particle by organic/ inorganic compounds) could be responsible for the MAE variability instead of the abundance of one combustion source (fossil fuel, wood burning) relatively to the other. This is consistent with Figure S4 (auxiliary material) which shows that periods with high MAE do coincide most of the time with pollution episodes (elevated $\mathrm{PM}_{2.5}$ values) that are favorable to an enhancement of the condensation of organic/ inorganic compounds onto soot particles. ${ }^{1}$ Based on these observations, we have assumed equivalent $\mathrm{MAE}$ for $\mathrm{BC}_{\mathrm{ff}}$ and $\mathrm{BC}_{\mathrm{wb}}$, and calculated these 2 fractions following the equation:

$$
\mathrm{BC}_{\mathrm{ff}}=\mathrm{BC} \times\left(\mathrm{b}_{\mathrm{abs}, \mathrm{ff}, 950 \mathrm{~nm}} / \mathrm{b}_{\mathrm{abs}, \mathrm{ff}, 950 \mathrm{~nm}}\right)
$$

\footnotetext{
${ }^{1}$ Auxiliary materials are available in the HTML. doi:10.1029/ 2011JD015756.
}

The details of the calculation of $\mathrm{C}_{1}, \mathrm{C}_{2}, \mathrm{C}_{3}$ (equation (3)) are presented below. The factor $\mathrm{C}_{1}$ can be calculated from the following equations:

$$
\begin{gathered}
\mathrm{BC}_{\mathrm{ff}}=\mathrm{b}_{\mathrm{abs}, \mathrm{ff}, 950 \mathrm{~nm} / \mathrm{MAE}} \\
\mathrm{OM}_{\mathrm{ff}}=f_{O C-O M} \times(\mathrm{OC} / \mathrm{EC})_{\mathrm{ff}} \times \mathrm{BC}_{\mathrm{ff}} \\
\mathrm{CM}_{\mathrm{ff}}=\mathrm{BC}_{\mathrm{ff}}+\mathrm{OM}_{\mathrm{ff}}
\end{gathered}
$$

where $\mathrm{BC}_{\mathrm{ff}}, \mathrm{OM}_{\mathrm{ff}}$, and $\mathrm{MAE}$, stand for $\mathrm{BC}, \mathrm{OM}$, and MAE from fossil fuel respectively; $f_{O C-O M}$ stands for the OC-OM conversion factor; and $(\mathrm{OC} / \mathrm{EC})_{\mathrm{ff}}$ stands for a typical $\mathrm{OC} / \mathrm{EC}$ ratio for fossil fuel emissions. The factor $\mathrm{C}_{1}$ can then be calculated using these 3 equations and equation (3) as:

$$
\mathrm{C}_{1}=\left[\left(1+f_{O C-O M} \times(\mathrm{OC} / \mathrm{EC})_{\mathrm{ff}}\right) / \mathrm{MAE}\right] .
$$

[33] The MAE of $7.3 \mathrm{~m}^{2} / \mathrm{g}$ calculated previously can be used here to calculate $\mathrm{BC}_{\mathrm{ff}}$ (equation (9)). A value of $1.3 \mathrm{can}$ be proposed here for $f_{O C-O M}$ assuming that organic aerosols originating from fossil fuel are mainly of primary origin and poorly oxygenated [Turpin and Lim, 2001; Zhang et al., 2005]. The choice of $(\mathrm{OC} / \mathrm{EC})_{\mathrm{ff}}$ may be difficult to obtain from our data set due to the presence of possibly elevated background concentrations of other organic aerosol sources (biomass burning, secondary organics). For that reason, we have taken a ratio of 0.70 obtained from semi-continuous EC and OC measurements we have performed (with the same ECOC Sunset Field instrument) in the city of Paris during springtime [Sciare et al., 2010]. This OC/EC ratio is close to those reported by Lonati et al. [2007] and El Haddad et al. [2009] for measurements performed in tunnels in Italy and France, respectively. It is also in line with the ratio of 0.7 suggested for the overall fossil fuel consumption in the EU15 area [Kupiainen and Klimont, 2007]. Based on these assumptions, a $C_{1}$ value of $2.616 \times 10^{5} \mu \mathrm{g} / \mathrm{m}^{2}$ was calculated here which is very close to the $\mathrm{C}_{1}$ values of $2.588 \times$ $10^{5} \mu \mathrm{g} / \mathrm{m}^{2}$ and $2.648 \times 10^{5} \mu \mathrm{g} / \mathrm{m}^{2}$ reported by Sandradewi et al. [2008a] and Favez et al. [2009], respectively.

[34] Hourly measurements obtained by the OCEC Sunset field and aethalometer instruments during the campaign $(12-21 / 06)$ were used to calculate every hour $b_{a b s, f f, 950 \mathrm{~nm}}$, $\mathrm{b}_{\mathrm{abs}, w b, 470 \mathrm{~nm}}$, and $\mathrm{CM}_{\text {total }}$. This data set $(\mathrm{N}=206)$ was used in equation (3) to derive $\mathrm{C}_{2}$ and $\mathrm{C}_{3}$ using a simple linear regression analysis. Values of $5.41 \times 10^{5} \pm 0.20 \times 10^{5} \mu \mathrm{g} / \mathrm{m}^{2}$ and $5.36 \pm 0.17 \mu \mathrm{g} / \mathrm{m}^{3}$ are obtained for these 2 coefficients, respectively. Our $\mathrm{C}_{2}$ value is $14 \%$ and $19 \%$ lower compared to the ones reported by Sandradewi et al. [2008a] and Favez et al. [2009], respectively. This discrepancy can be due to different analytical methods used to determine $\mathrm{CM}$ concentrations. Our CM data set was based on hourly VOCdenuded semi-continuous EC and OC concentrations, whereas the CM data set used by Sandradewi et al. [2008a] was based on AMS measurements and the CM data set used by Favez et al. [2009] was based on undenuded $24 \mathrm{~h}$ filterbased EC and OC concentrations. Note also that Favez et al. [2010] have reported different $C_{2}$ values when using either filter-based EC and OC measurements or AMS measurements. 


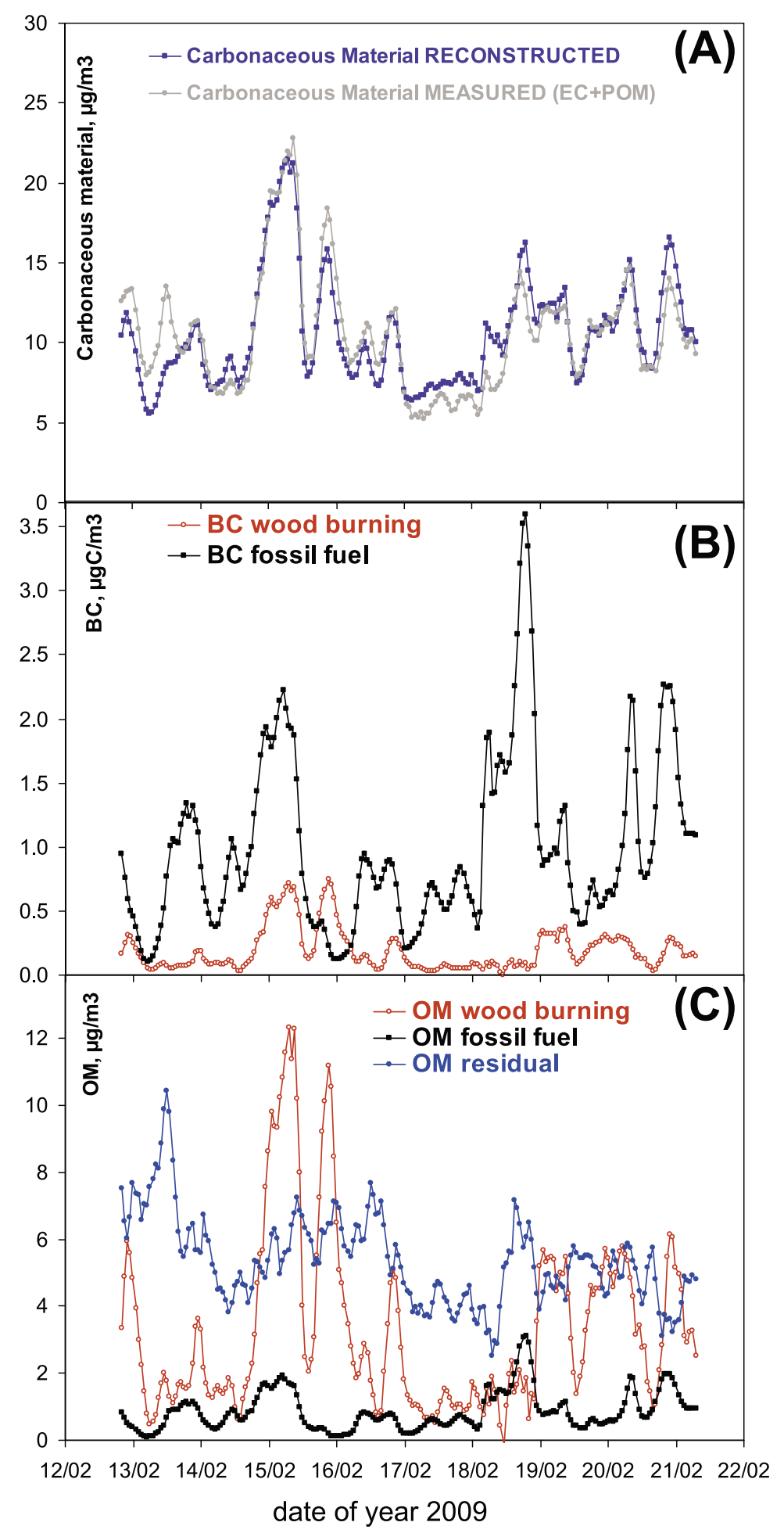

Figure 4. Results of the aethalometer model: (a) Comparison between measured and reconstructed carbonaceous material. (b) Temporal variations of fossil fuel and wood burning black carbon. (c) Temporal variations of fossil fuel, wood burning, and residual (SOA) organic matter.

Finally, the $\mathrm{C}_{2}$ value may not be necessary identical from one study to another. As illustrated in equation (11) for the calculation of $\mathrm{C}_{1}$ (fossil fuel), $\mathrm{C}_{2}$ may depend on various factors such as the MAE for wood burning as well as the
$\mathrm{OM}_{\mathrm{wb}} / \mathrm{EC}_{\mathrm{wb}}$, both factors being dependent on parameters such as combustion efficiencies and/or biofuel types.

[35] Results of the aethalometer model are illustrated in Figure $4 \mathrm{a}$ which reports the comparison between the 
measured and reconstructed carbonaceous matter (CM). This comparison shows a slope close to one (0.99) and a good correlation coefficient $\left(\mathrm{r}^{2}=0.89 ; \mathrm{N}=204\right)$. This model appears to be consistent with the measurements performed with the OCEC sunset field instrument and well constrained
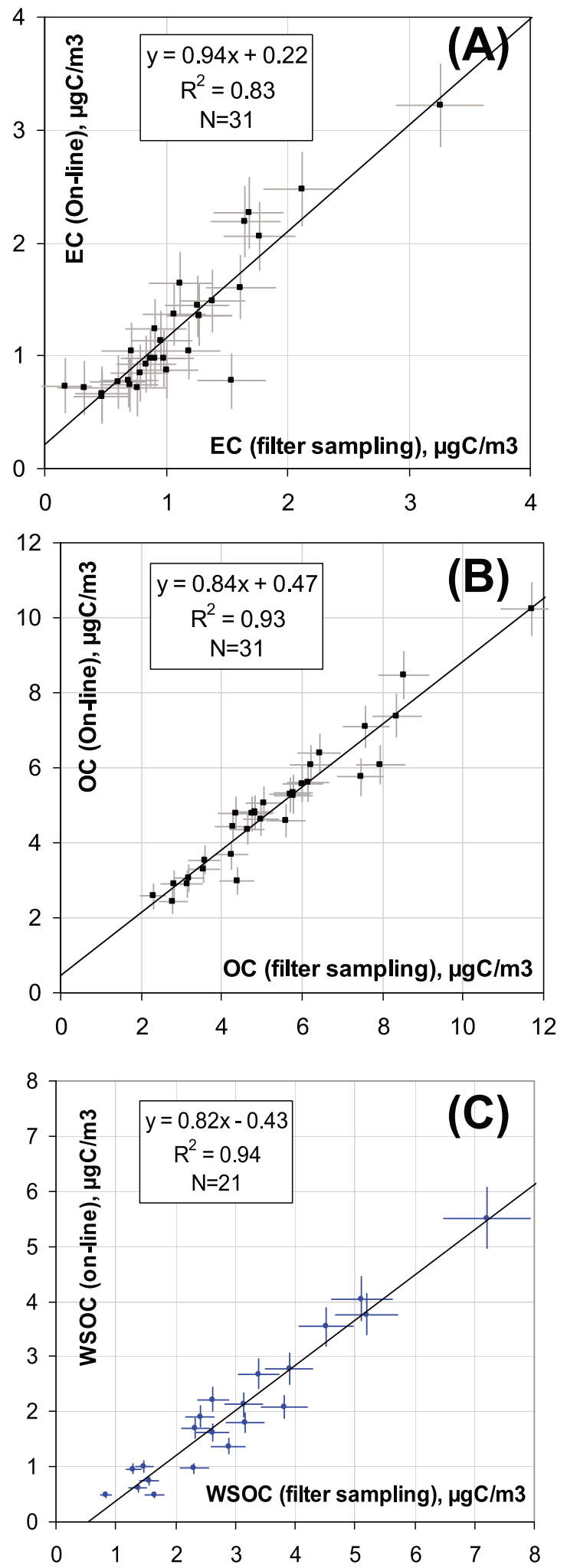

by the large number of EC and $\mathrm{OC}$ data points obtained by this instrument.

\section{Results}

4.1. Comparison Between Online and Filter Sampling Measurements of EC, OC, and WSOC

[36] Filter-based measurements of EC and OC were compared with the results obtained by the (online) OCEC Sunset field instrument. Results are reported in Figures 5a and $5 \mathrm{~b}$. Error bars reported in Figure 5 stand for the uncertainties in $\mathrm{OC}$ and $\mathrm{EC}$ concentrations following the recommendation of the manufacturer. Figure 5 shows a high correlation coefficient of $r^{2}=0.83$ and $r^{2}=0.93$ for EC and $\mathrm{OC}$, respectively. The intercepts were close to 0 and slopes close to one (0.94 and 0.84 for EC and OC, respectively). Sample-to-sample comparison has shown similar good agreement with median difference values of 11.6 and $7.4 \%$ for $\mathrm{EC}$ and $\mathrm{OC}$, respectively.

[37] The same filter samples were compared for their concentrations in WSOC with the PILS-TOC instrument. Results are reported in Figure $5 \mathrm{c}$ and show a good agreement between the two techniques $\left(\mathrm{r}^{2}=0.94, \mathrm{~N}=21\right)$. Intercept was found close to $0\left(-0.43 \mu \mathrm{gC} / \mathrm{m}^{3}\right)$ and the slope showed an $18 \%$ overestimation from the filter sampling technique. Sample-to-sample comparison between these two techniques shows a median difference value of $38.4 \%$ $\left(\sim 1 \mu \mathrm{gC} / \mathrm{m}^{3}\right)$ in favor of the filter sampling and confirms the overestimation of WSOC given from the filter sampling.

[38] Filter sampling artifacts may probably be responsible for the almost constant overestimation of about $1 \mu \mathrm{gC} / \mathrm{m}^{3}$ of WSOC. Although a VOC denuder was placed upstream to the filter sampling, VOCs may still have passed through this denuder and be adsorbed on the active sites of the filter matrix. This artifact is not observed with the PILS-TOC technique which avoids filter media for collecting particles.

[39] Note that online and off-line OC measurements may be affected by similar positive and negative sampling artifacts, since they are based on filter sampling techniques. This is not the case for online and off-line WSOC measurements which may explain why the OC intercomparison appears slightly better than the WSOC intercomparison. Note also that discrepancies between online and filter sampling WSOC (and OC) measurements may also be explained by evaporative losses of (semi-volatile) organic aerosols into the online instruments (OCEC Sunset field and PILSTOC instruments) when the sample air was drawn from the cold outdoor to the warm indoor environment. In order to reduce such heat up of the sampled air, the length of inlet tubing for the online instruments exposed to room temperature was reduced, being $1 \mathrm{~m}$ or below.

Figure 5. Comparison between online (OCEC Sunset Field instrument and PILS-TOC) and off-line (Partisol Plus filter sampling) measurements for (a) Elemental Carbon (EC), (b) Organic Carbon (OC), and (c) water-soluble Organic Carbon (WSOC). Error bars for EC and OC are calculated following the analytical uncertainty given for the Sunset instrument $\left(0.2 \mu \mathrm{g} \mathrm{C} / \mathrm{cm}^{2} \pm 5 \%\right)$. Error bars for WSOC are calculated using the $10 \%$ uncertainty estimated for this compound. 
Table 1. Atmospheric Concentrations of the Different Carbonaceous Fractions in Fine Aerosols $(\mathrm{AD}<2.5 \mu \mathrm{m})$ for the Period $(12-21 / 02 / 2009)^{\mathrm{a}}$

\begin{tabular}{lccc}
\hline Compound & Unit & Range & Mean Concentrations $( \pm 1 \sigma)$ \\
\hline $\mathrm{BC}$ & $\mu \mathrm{gC} / \mathrm{m}^{3}$ & $0.15-3.36$ & $0.97( \pm 0.61)$ \\
$\mathrm{OC}$ & $\mu \mathrm{gC} / \mathrm{m}^{3}$ & $2.32-12.05$ & $5.27( \pm 1.84)$ \\
WSOC & $\mu \mathrm{gC} / \mathrm{m}^{3}$ & $0.02-6.18$ & $2.08( \pm 1.31)$ \\
Levoglucosan & $\mu \mathrm{g} / \mathrm{m}^{3}$ & $0.072-0.919$ & $0.28( \pm 0.22)$ \\
$\mathrm{BC}_{\mathrm{ff}}$ & $\mu \mathrm{gC} / \mathrm{m}^{3}$ & $0.10-3.49$ & $0.96( \pm 0.66)$ \\
$\mathrm{BC}_{\mathrm{wb}}$ & $\mu \mathrm{gC} / \mathrm{m}^{3}$ & $0.00-0.81$ & $0.22( \pm 0.18)$ \\
$\mathrm{OM}_{\mathrm{ff}}$ & $\mu \mathrm{g} / \mathrm{m}^{3}$ & $0.09-3.17$ & $0.88( \pm 0.60)$ \\
$\mathrm{OM}_{\mathrm{wb}}$ & $\mu \mathrm{g} / \mathrm{m}^{3}$ & $0.00-12.33$ & $3.33( \pm 2.67)$ \\
$\mathrm{OM}_{\mathrm{residual}}$ & $\mu \mathrm{g} / \mathrm{m}^{3}$ & $1.33-10.45$ & $5.36( \pm 1.33)$ \\
\hline
\end{tabular}

${ }^{\mathrm{a} C}$ Calculations are based on hourly averaged data.

[40] Note that possible evaporative losses of (semi-volatile) organic aerosols into the online instruments may be more important when the temperature gradient is high between outdoor and indoor conditions. Concentrations of OC should be particularly affected by such evaporative losses since the temperature of the filter inside the Sunset Field instrument is typically $20^{\circ} \mathrm{C}$ during the sampling step. In order to investigate this possibility, we have plotted in auxiliary material (Figure S1) the off-line to online OC ratio as a function of the outdoor temperature. No relationship was observed suggesting that differences observed between the two techniques (off-line and online) could not be explained by temperature gradient (between outdoor and indoor conditions).

\subsection{Source Apportionment of Carbonaceous Aerosols Using the Aethalometer Model}

[41] Based on the availability of the aethalometer model to properly reproduce temporal variations of $\mathrm{CM}$ determined experimentally, we have decided to modify (enhance) this model in order to document hourly concentrations of noncombustion organic aerosols. To do so, $\mathrm{OM}_{\text {residual was not }}$ set as a constant value any more but was deduced from equation (3) by the difference between $\mathrm{CM}$ and $\left(\mathrm{CM}_{\mathrm{ff}}+\right.$ $\mathrm{CM}_{\mathrm{wb}}$ ) determined previously. Doing so, SOA concentrations (assumed here to refer to $\mathrm{OM}_{\text {residual }}$ ) were then obtained every hour. It is important to note here that the use of a variable concentration of SOA represents the main difference between our (modified) aethalometer model and those previously reported in literature.

[42] Temporal variations of the different carbonaceous fractions $(\mathrm{BC}, \mathrm{OM})$ are reported in Figures $4 \mathrm{~b}$ and $4 \mathrm{c}$. The two combustion sources (fossil fuel and biomass burning) exhibit quite different patterns. High concentrations of wood burning aerosols are observed almost every evening with the highest concentrations during the week-end (14-15/02) which corresponds to the coldest period of our study with hourly mean air temperature minima of $-3^{\circ} \mathrm{C}$. Note also that the lowering of the planetary boundary layer (PBL) height at night may have also enhanced significantly the nighttime concentrations of wood burning aerosols. A clear double maximum is observed during daytime for $\mathrm{BC}$ originating from fossil fuel (the 16,17, 19 and 21/02) and can be attributed to traffic emissions since these 2 maxima are observed at rush hours (08:00-10:00 LT and 18:00-21:00 LT). The temporal variations of SOA $\left(\mathrm{OM}_{\text {residual }}\right)$ are reported in Figure $4 \mathrm{c}$ and show significant concentration levels ranging from 1.3 to $10.4 \mu \mathrm{g} / \mathrm{m}^{3}$ (average $5.38 \pm 1.33 \mu \mathrm{g} / \mathrm{m}^{3}$ ). These variations are disconnected (and less variable) from those observed for fossil fuel and wood burning and will be discussed in more details in the following.

[43] Atmospheric concentrations of the different carbonaceous fractions are summarized in Table 1. During our study, the relative contribution of $\mathrm{BC}_{\mathrm{wb}}$ to the total $\mathrm{BC}$ was highly variable ranging from 0 to $79 \%$ with, however, a rather small mean contribution $(25 \pm 16 \%)$. The wood burning source $\left(\mathrm{CM}_{\mathrm{wb}}\right)$ contributes on average to $61 \%$ of the total mass of combustion aerosols (29\% to the total mass of $\mathrm{CM}$ ). Contribution of these wood burning aerosols to $\mathrm{PM}_{2.5}$ ranges from 0 to $55 \%$ (average of $15 \pm 11 \%$ ).

[44] Our wood burning contribution of $61 \%$ (relative to combustion aerosols) is significantly higher compared to the $46 \%$ reported by Favez et al. [2009] for a background urban site in Paris during winter 2005. Lower traffic emissions combined with larger residential areas (i.e., stronger domestic wood burning emissions) at our suburban site may explain this discrepancy. This discrepancy may also originate from the time period of our study which encompassed school holidays, leading to less traffic and possibly higher domestic heating emissions.

[45] Another comparison can be performed with a recent source apportionment study of carbonaceous aerosols performed in Grenoble (France) during the same period (winter 2009) and using also the aethalometer model [Favez et al., 2010]. These authors found that $83 \%$ of BC in Grenoble originated from fossil fuel which is close to our value of $75 \%$. Values of $\mathrm{OM}_{\mathrm{ff}}, \mathrm{OM}_{\mathrm{wb}}$, and $\mathrm{OM}_{\text {residual }}$ were found to contribute to about $14 \%, 56 \%$, and $30 \%$, respectively of OM, which are comparable to ours $(10 \%, 31 \%$, and $59 \%$, respectively).

[46] Our large contribution of $\mathrm{OM}_{\text {residual }}\left(5.38 \pm 1.33 \mu \mathrm{g} / \mathrm{m}^{3}\right.$ on average) strongly suggests that non-combustion OA (i.e., SOA) are playing a major role during wintertime. This concentration is consistent with the $5.9 \mu \mathrm{gC} / \mathrm{m}^{3}$ reported by Gilardoni et al. [2011] for secondary organic carbon at a European rural site during wintertime.

[47] Diurnal variations of the 3 OM sources have been investigated and show consistent temporal variability with a maximum in the evening (21:00-23:00) for the wood burning source corresponding to the domestic heating period (Figure 6a), and a double maximum for the fossil fuel source consistent with the 2 traffic peaks (08:00-10:00 and 18:00 21:00) (Figure 6b). The diurnal variations of $\mathrm{OM}_{\text {residual }}$ show a double peak, one during midday and another one after the night maximum of wood burning (Figure 6c). This pattern will be discussed later in section 5 .

\subsection{Sensitivity Study of the Aethalometer Model}

[48] The purpose of this section is to test the sensitivity of the Aethalometer model on the few assumptions we have used in this model regarding $\mathrm{CM}$ (i.e., $\mathrm{f}_{\mathrm{OC}-\mathrm{OM}}$ ), $\mathrm{C}_{1}$ (i.e., $\mathrm{f}_{\mathrm{OC}-\mathrm{OM}}$, $\left.\left.(\mathrm{OC} / \mathrm{EC})_{\mathrm{ff}}\right), \mathrm{MAE}_{\mathrm{ff}}\right), \alpha_{\mathrm{ff}}$, and $\alpha_{\mathrm{wb}}$. Uncertainties associated with atmospheric measurements will not be addressed here as they have been discussed previously from the comparison with the filter sampling (section 4.1).

\subsubsection{Influence of $f_{O C-O M}$ on the Results} of the Aethalometer Model

[49] Although the aethalometer model reported in previous studies has been used solely to reconstruct CM, this model 


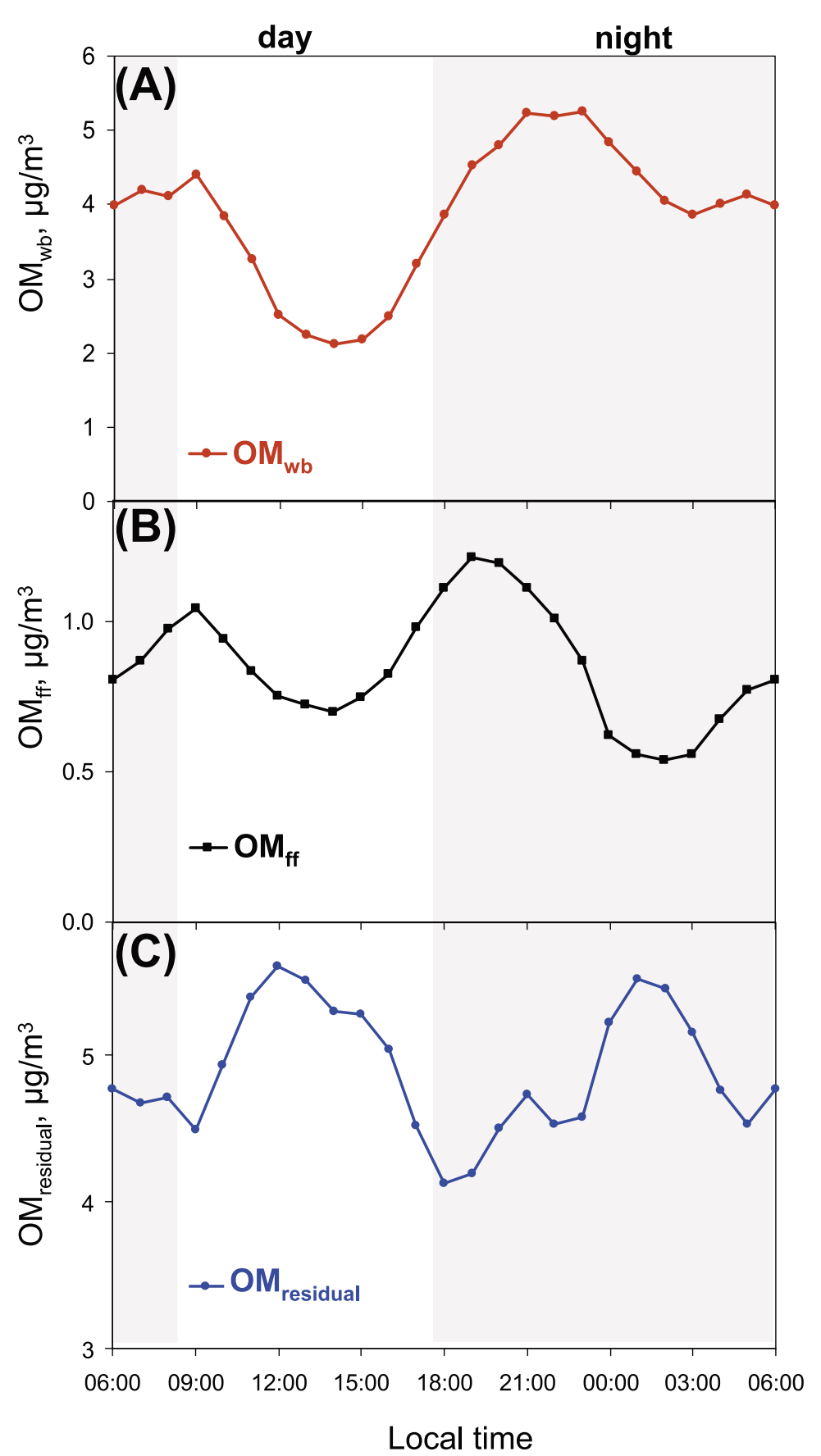

Figure 6. Diurnal variations of (a) $\mathrm{OM}$ from the wood burning combustion source $\left(\mathrm{OM}_{\mathrm{wb}}\right)$, (b) $\mathrm{OM}$ from fossil fuel combustion source $\left(\mathrm{OM}_{\mathrm{ff}}\right)$, and (c) $\mathrm{OM}$ from the residual (secondary) organic source $\left(\mathrm{OM}_{\text {residual }}\right)$. The gray zones stand for nighttime.

can also be used to reconstruct total carbon (TC) following exactly the same methodology as for $\mathrm{CM}$ (see section 3 ). The main interest to reconstruct TC from OC measurements is that no assumptions are needed regarding the choice of $\mathrm{f}_{\mathrm{OC}-\mathrm{OM}}$. These assumptions concern the determination of $\mathrm{CM}$ and $\mathrm{C}_{1}$. Results of the TC reconstruction are reported in the auxiliary material (Figures S2 and S3). Results are very similar as those reported for CM reconstruction. The correlation coefficient $\left(\mathrm{r}^{2}\right)$ of 0.77 between measured and reconstructed TC is similar to the one found between measured and reconstructed CM (0.79).

\subsubsection{Influence of $\alpha_{\mathrm{ff}}$ on the Results} of the Aethalometer Model

[50] We have let here $\alpha_{\mathrm{ff}}$ range from 0.8 to 1.2 (keeping $\alpha_{\mathrm{wb}}=2.0$ ). These values stand for the maximum range of commonly reported $\alpha_{\mathrm{ff}}$ in literature [Kirchstetter et al., 2004; Schnaiter et al., 2003, 2005]. Results are summarized in Table 2 and compared with the base case $\left(\alpha_{\mathrm{ff}}=1.1\right)$. The $\alpha_{\mathrm{ff}}$ value of 1.2 was found to be unrealistic (leading, for some periods, to negative values for $\mathrm{BC}_{\mathrm{wb}}$ and $\mathrm{OM}_{\mathrm{wb}}$ ). Although scenarios with $\alpha_{\mathrm{ff}}$ values of 0.9 and 1.0 cannot be excluded, they lead to lower correlation coefficients 
Table 2. Results of the Sensitivity Tests of the Aethalometer Model for Different Scenarios With Variable $\alpha_{\mathrm{ff}}, \alpha_{\mathrm{wb}}$, and $\mathrm{C}_{1}{ }^{\mathrm{a}}$

\begin{tabular}{|c|c|c|c|c|c|c|c|c|c|c|c|c|}
\hline Scenario & $\mathrm{C} 1$ & $\mathrm{C} 2$ & $\mathrm{C} 3$ & $\alpha_{\mathrm{ff}}$ & $\alpha_{\mathrm{wb}}$ & $\mathrm{r}^{2 \mathrm{~b}}$ & $\begin{array}{c}\text { Percent } \\
\text { Difference } \\
\mathrm{BC}_{\mathrm{ff}}^{\mathrm{c}}\end{array}$ & $\begin{array}{c}\text { Percent } \\
\text { Difference } \\
\mathrm{BC}_{\mathrm{wb}}^{\mathrm{c}}\end{array}$ & $\begin{array}{c}\text { Percent } \\
\text { Difference } \\
\mathrm{OM}_{\mathrm{ff}}^{\mathrm{c}}\end{array}$ & $\begin{array}{c}\text { Percent } \\
\text { Difference } \\
\mathrm{OM}_{\mathrm{wb}}^{\mathrm{c}}\end{array}$ & $\begin{array}{c}\text { Percent } \\
\text { Difference } \\
\text { OM }_{\text {residual }}\end{array}$ & Remark \\
\hline$\alpha_{\mathrm{ff}}=0.9$ & 0.262 & 0.421 & 4.819 & 0.9 & 2 & 0.65 & $-14 \%$ & $+42 \%$ & $-14 \%$ & $+18 \%$ & $-11 \%$ & \\
\hline$\alpha_{\mathrm{ff}}=1.0$ & 0.262 & 0.484 & 4.868 & 1 & 2 & 0.72 & $-7 \%$ & $+25 \%$ & $-7 \%$ & $+16 \%$ & $-10 \%$ & \\
\hline$\alpha_{\mathrm{ff}}=1.1$ & 0.262 & 0.541 & 5.363 & 1.1 & 2 & 0.79 & $0 \%$ & $0 \%$ & $0 \%$ & $0 \%$ & $0 \%$ & base case \\
\hline$\alpha_{\mathrm{ff}}=1.2$ & 0.262 & 0.529 & 6.643 & 1.2 & 2 & 0.76 & $+9 \%$ & $-45 \%$ & $+9 \%$ & $-52 \%$ & $+21 \%$ & $\begin{array}{c}\text { negative } \mathrm{BC}_{\mathrm{wb}} \\
\text { and } \mathrm{OM}_{\mathrm{wb}} \text { values }\end{array}$ \\
\hline$\alpha_{\mathrm{wb}}=1.8$ & 0.262 & 0.469 & 5.363 & 1.1 & 1.8 & 0.81 & $-9 \%$ & $+33 \%$ & $-9 \%$ & $+3 \%$ & $0 \%$ & $\begin{array}{c}\text { negative } \mathrm{BC}_{\mathrm{ff}} \\
\text { and } \mathrm{OM}_{\mathrm{ff}} \text { values }\end{array}$ \\
\hline$\alpha_{\mathrm{wb}}=1.9$ & 0.262 & 0.510 & 5.363 & 1.1 & 1.9 & 0.79 & $-4 \%$ & $+16 \%$ & $-4 \%$ & $+1 \%$ & $0 \%$ & \\
\hline$\alpha_{\mathbf{w b}}=\mathbf{2 . 0}$ & 0.262 & 0.541 & 5.363 & 1.1 & 2 & 0.79 & $0 \%$ & $0 \%$ & $0 \%$ & $0 \%$ & $0 \%$ & base case \\
\hline$\alpha_{\mathrm{wb}}=2.1$ & 0.262 & 0.573 & 5.363 & 1.1 & 2.1 & 0.77 & $+3 \%$ & $-14 \%$ & $+3 \%$ & $-1 \%$ & $0 \%$ & \\
\hline$\alpha_{\mathrm{wb}}=2.2$ & 0.262 & 0.603 & 5.363 & 1.1 & 2.2 & 0.77 & $+5 \%$ & $-28 \%$ & $+5 \%$ & $-2 \%$ & $0 \%$ & \\
\hline $\mathrm{C} 1=0.1867$ & 0.187 & 0.552 & 5.813 & 1.1 & 2 & 0.79 & $0 \%$ & $0 \%$ & $-64 \%$ & $+2 \%$ & $+8 \%$ & \\
\hline $\mathrm{C} 1=0.2616$ & 0.262 & 0.541 & 5.363 & 1.1 & 2 & 0.79 & $0 \%$ & $0 \%$ & $\mathbf{0 \%}$ & $0 \%$ & $0 \%$ & base case \\
\hline $\mathrm{C} 1=0.3730$ & 0.373 & 0.449 & 4.443 & 1.1 & 2 & 0.74 & $0 \%$ & $0 \%$ & $+53 \%$ & $-4 \%$ & $-13 \%$ & \\
\hline
\end{tabular}

${ }^{\mathrm{a}}$ Base case (used in this paper) is reported in bold.

${ }^{\mathrm{b}}$ Correlation coefficient between CM measured and CM reconstructed.

${ }^{\mathrm{c}}$ Percentage difference calculated from the base case.

between measured and reconstructed $\mathrm{CM}\left(\mathrm{r}^{2}=0.65\right.$ and 0.72 for $\alpha_{\mathrm{ff}}$ values of 0.9 and 1.0 , respectively) by comparison with the base case $\left(r^{2}=0.79\right)$. Our $\alpha_{\mathrm{ff}}$ value appears here to lead to the best agreement between measured and reconstructed $\mathrm{CM}$, even though our $\alpha_{\mathrm{ff}}$ value of 1.1 was directly deduced from field measurements (when the traffic source contribution was the highest; Figure 3) and was consistent with literature data. As shown in Table 2, the use of $\alpha_{\mathrm{ff}}$ values of 0.9 and 1.0 do not lead to significant changes in the $\mathrm{BC}$ and $\mathrm{OM}$ concentrations from the 3 different sources (except for $\mathrm{BC}_{\mathrm{wb}}$ concentrations), with slightly lower concentration levels of $\mathrm{OM}_{\text {residual }}(\sim-10 \%)$ These slight changes will not alter the main conclusions of the paper regarding the major contribution of SOA $\left(\mathrm{OM}_{\text {residual }}\right)$.

\subsubsection{Influence of $\alpha_{\mathrm{wb}}$ on the Results} of the Aethalometer Model

[51] We have let here $\alpha_{\mathrm{wb}}$ range from 1.8 to 2.2 (keeping $\alpha_{\mathrm{ff}}=1.1$ ). As shown in Table 2, the choice of $\alpha_{\mathrm{wb}}$ appears much less sensitive than $\alpha_{\mathrm{ff}}$. Comparison between measured and reconstructed CM shows a correlation coefficient of $\mathrm{r}^{2}$ ranging from 0.81 to 0.77 for $\alpha_{\mathrm{wb}}$ ranging from 1.8 to 2.2. An $\alpha_{\mathrm{wb}}$ value of 1.8 leads, for some periods of the campaign, to negative concentrations of $\mathrm{BC}_{\mathrm{ff}}$, and $\mathrm{OM}_{\mathrm{ff}}$. The use of $\alpha_{\mathrm{wb}}$ values ranging from 1.9 to 2.2 does not lead to significant changes in the $\mathrm{BC}$ and $\mathrm{OM}$ concentrations from the 3 different sources (except for $\mathrm{BC}_{\mathrm{wb}}$ concentrations); $\mathrm{OM}_{\text {residual }}$ concentrations remaining unchanged. For that reason, it can be concluded here that hypotheses related to the choice of a specific $\alpha_{\mathrm{wb}}$ value will not alter the main conclusions of the paper regarding the major contribution of SOA $\left(\mathrm{OM}_{\text {residual }}\right)$.

\subsubsection{Influence of $\mathrm{C}_{1}$ on the Results}

of the Aethalometer Model

[52] As defined in equation (11), $\mathrm{C}_{1}$ is a function of 3 parameters; $\mathrm{f}_{\mathrm{OC}-\mathrm{OM}},(\mathrm{OC} / \mathrm{EC})_{\mathrm{ff}}$, and $\mathrm{MAE}_{\mathrm{ff}}$, assigned to be $1.3,0.7$, and $7.3 \mathrm{~m}^{2} / \mathrm{g}$, respectively (see section 3 ). We have let here $\mathrm{f}_{\mathrm{OC}-\mathrm{OM}}$ range from 1.1 to $1.5,(\mathrm{OC} / \mathrm{EC})_{\mathrm{ff}}$ range from 0.5 to 0.9 , and $\mathrm{MAE}_{\mathrm{ff}}$ range from 6.3 to $8.3 \mathrm{~m}^{2} / \mathrm{g}$. These different ranges can be considered as covering the maximum variability of each parameter. Based on these different ranges, one minimum $C_{1}$ value of $1.867 \times 10^{5}$ (corresponding to $\left.\mathrm{f}_{\mathrm{OC}-\mathrm{OM}}=1.1 ;(\mathrm{OC} / \mathrm{EC})_{\mathrm{ff}}=0.5 ; \mathrm{MAE}_{\mathrm{ff}}=8.3 \mathrm{~m}^{2} / \mathrm{g}\right)$ and one maximum $\mathrm{C}_{1}$ value of $3.730 \times 10^{5}$ (corresponding to $\left.\mathrm{f}_{\mathrm{OC}-\mathrm{OM}}=1.5 ;(\mathrm{OC} / \mathrm{EC})_{\mathrm{ff}}=0.9 ; \mathrm{MAE}_{\mathrm{ff}}=6.3 \mathrm{~m}^{2} / \mathrm{g}\right)$ were taken here as an input parameter for the aethalometer model. These 2 scenarios were compared in Table 2 with the base case $\left(\mathrm{C}_{1}=2.616 \times 10^{5}\right)$. Except for $\mathrm{OM}_{\mathrm{ff}}$ concentrations - which have shown to vary by almost $50 \%$ - the use of a large range of $\mathrm{C}_{1}$ values do not strongly affect our $\mathrm{BC}$ and $\mathrm{OM}$ results, providing further confidence on our conclusions of an important source of SOA ( $\left.\mathrm{OM}_{\text {residual }}\right)$.

\subsection{Comparison of the Aethalometer Model Results With Other Tracers of Fossil Fuel and Wood Burning Combustion}

[53] The ability of the aethalometer model to properly derive $\mathrm{BC}$ and $\mathrm{OM}$ from both fossil fuel and wood burning is a critical issue in the determination of $\mathrm{OM}_{\text {residual }}$ concentrations (assessed as SOA in the present study). The consistency of this model was tested for that purpose against different real-time measurements of fossil fuel and wood burning tracers performed in parallel during our study. Results of these comparisons are presented here.

\subsubsection{Biomass Burning Tracers}

4.4.1.1. Water-Soluble Potassium

[54] Water-soluble potassium, mainly emitted in the form of $\mathrm{KCl}$ during biomass burning combustion, can be produced in different amounts depending on fuel and combustion types making difficult its use to properly quantify wood burning aerosols [Puxbaum et al., 2007; Sullivan et al., 2008]. At a given location and for a limited period where fuel type and combustion processes are homogeneous, emission of potassium in the atmosphere may remain quite stable allowing its use to follow the concentration of wood burning aerosols. Hence, once emitted in the atmosphere, potassium will not undergo aging like other wood burning tracers such as levoglucosan [Hennigan et al., 2010]. Time-resolved water-soluble potassium measurements were performed during our study every $10 \mathrm{~min}$ by the PILS-IC and are reported in Figure $7 \mathrm{a}$ together with $\mathrm{BC}_{\mathrm{wb}}$ for the periods of the campaign when the PILS-IC was operating. Comparison between these 2 data sets shows most of the time a good 


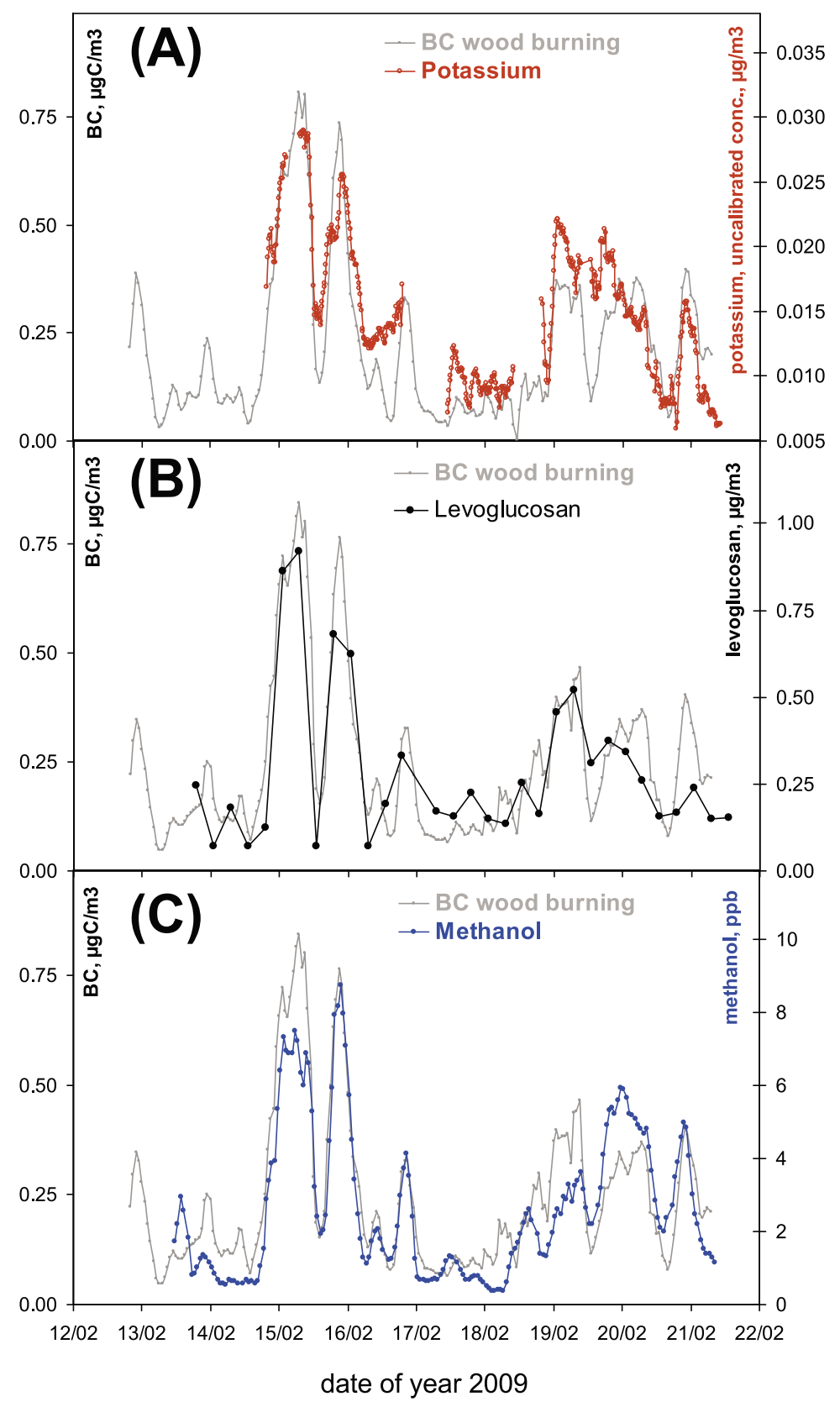

Figure 7. Comparison of black carbon from wood burning $\left(\mathrm{BC}_{\mathrm{wb}}\right)$ obtained with the aethalometer model with: (a) co-located online measurements of water-soluble potassium obtained by PILS-IC, (b) co-located filter-based measurements of levoglucosan, and (c) co-located online measurements of methanol obtained by PTR-MS.

accordance $\left(\mathrm{r}^{2}=0.71 ; \mathrm{N}=129\right)$ with concomitant maxima (nights of 15, 16, 19, 20, and 21/02). This good accordance between two compounds of biomass burning aerosols obtained independently brings further confidence on the aethalometer model results and points also to the potential use of a real-time determination of water-soluble potassium by PILS-IC as a useful tracer to follow biomass burning aerosols.

\subsubsection{Levoglucosan}

[55] This compound, produced by the combustion of cellulose, is widely used to derive in a quantitative way the contribution of primary biomass burning smoke to the total organic carbon [Puxbaum et al., 2007; Sullivan et al., 2008; Sandradewi et al., 2008b; Szidat et al., 2009]. During our study, levoglucosan concentrations obtained from filter sampling were ranging from 0.072 to $0.919 \mu \mathrm{g} / \mathrm{m}^{3}$ with a mean concentration of $0.28 \pm 0.22 \mu \mathrm{g} / \mathrm{m}^{3}$ (Table 1). This concentration falls in the medium range of those reported for European urban areas during wintertime [Szidat et al., 2009]. Comparison between hourly concentrations of $\mathrm{BC}_{\mathrm{wb}}$ and $6-\mathrm{h}$ integrated levoglucosan concentrations is reported in Figure 7b. Correlation between $\mathrm{OM}_{\mathrm{wb}}$ and levoglucosan 


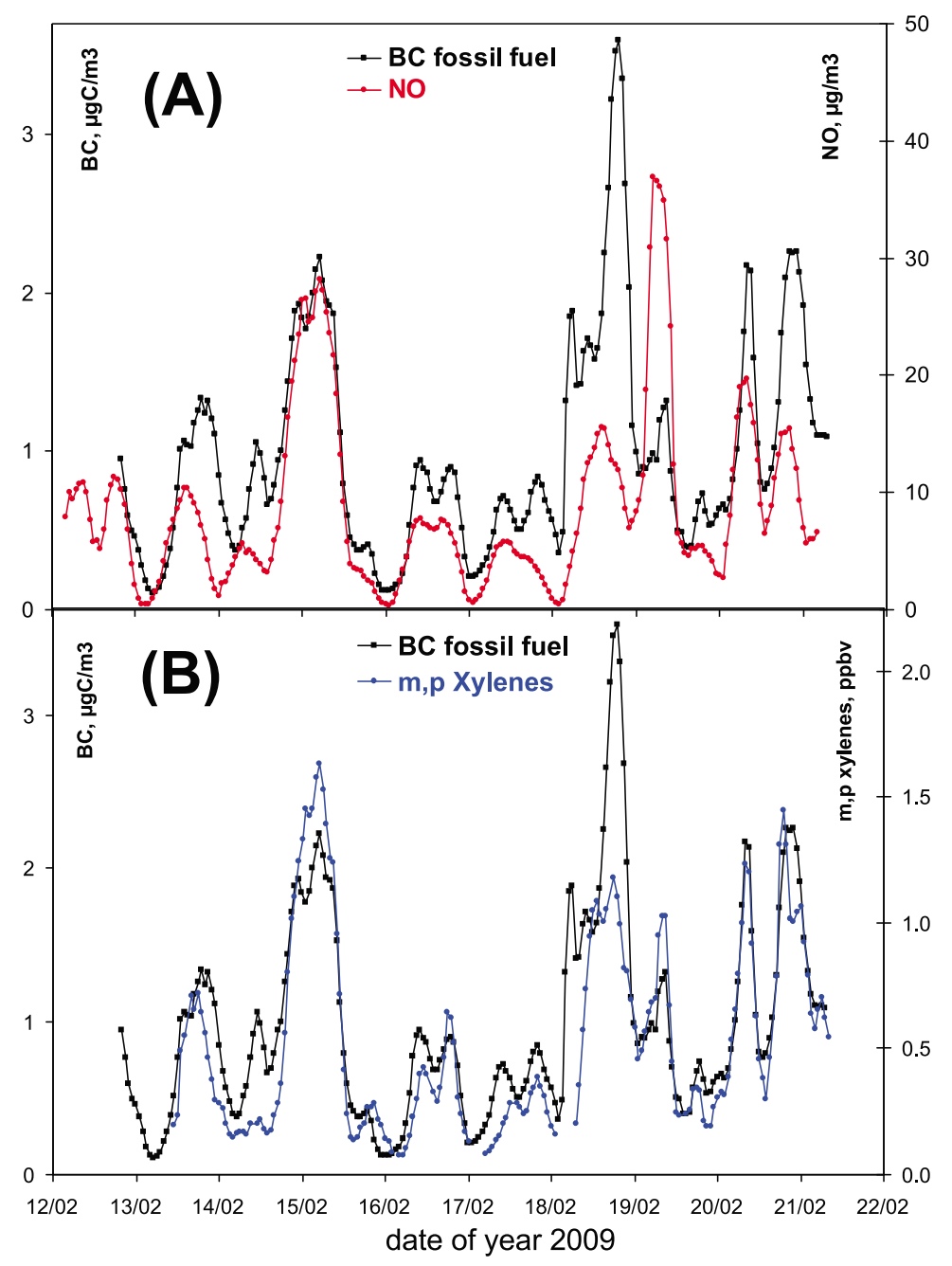

Figure 8. Comparison of black carbon from fossil fuel $\left(\mathrm{BC}_{\mathrm{ff}}\right)$ obtained with the aethalometer model with: (a) nitric oxide (NO) obtained from the local air quality network at $20 \mathrm{~km}$ distance from our station, and (b) co-located online measurements of m,p-xylenes obtained by GC-FID.

is satisfactory $\left(\mathrm{r}^{2}=0.66\right)$ and leads to a slope of about $10.3 \mu \mathrm{g} / \mu \mathrm{g}$, which is close to the $\mathrm{OM}_{\mathrm{wb}} /$ levoglucosan ratio of 10.8 reported by Favez et al. [2010] for the city of Grenoble (France). This ratio corresponds to an $\mathrm{OC}_{\mathrm{wb}} /$ levoglucosan ratio of $6.2 \mu \mathrm{gC} / \mu \mathrm{g}$, when using an OC-OM conversion factor of 1.7 for $\mathrm{OM}_{\mathrm{wb}}$ [Puxbaum et al., 2007, and references therein]. This ratio is in the range of the values of 6-7 reported by Puxbaum et al. [2007] which should be representative for domestic heating in European countries.

\subsubsection{Methanol}

[56] This oxygenated VOC is one of the most significant organic compounds in the atmosphere and has been reported as a major primary product of biomass burning [Holzinger et al., 2005; de Gouw et al., 2006; Gaeggeler et al., 2008], with secondary production in aged biomass burning playing a minor role [Karl et al., 2007]. A methanol-to-acetonitrile average ratio of $13.6 \pm 7.6$ (ppbv/ppbv) obtained during our study falls in the range of those reported for biomass burning conditions [Holzinger et al., 2005; Karl et al., 2007]. Comparison of hourly mean concentrations of methanol and $\mathrm{BC}_{\mathrm{wb}}$ is reported in Figure 7c and exhibits very similar temporal variations $\left(r^{2}=0.77 ; \mathrm{N}=183\right)$ with, however, some differences in terms of maxima that could be partly explained by changes in background concentrations of methanol governed by air mass origin. Similar good agreement with $\mathrm{BC}_{\mathrm{wb}}$ can be found with acetonitrile another VOC emitted in large quantity by biomass burning (data not shown here).

\subsubsection{Fossil Fuel Tracers \\ 4.4.2.1. Nitric Oxide (NO)}

[57] This compound is a well-known tracer of primary fossil fuel combustion which is often used in literature to support the role of traffic emissions on BC concentrations [see, e.g., Jiang et al., 2005, and references therein]. Such measurements were available from two stations of the local air quality network (AIRPARIF) located respectively at $20 \mathrm{~km}$ north and south of our measurement site. Averaged NO concentrations from these 2 stations are reported in Figure $8 \mathrm{a}$ together with $\mathrm{BC}_{\mathrm{ff}}$. Although very local traffic emissions may significantly alter NO measurements performed at $20 \mathrm{~km}$ distance from our station, a relatively good agreement is observed with $\mathrm{BC}_{\mathrm{ff}}\left(\mathrm{r}^{2}=0.56 ; \mathrm{N}=199\right)$. 


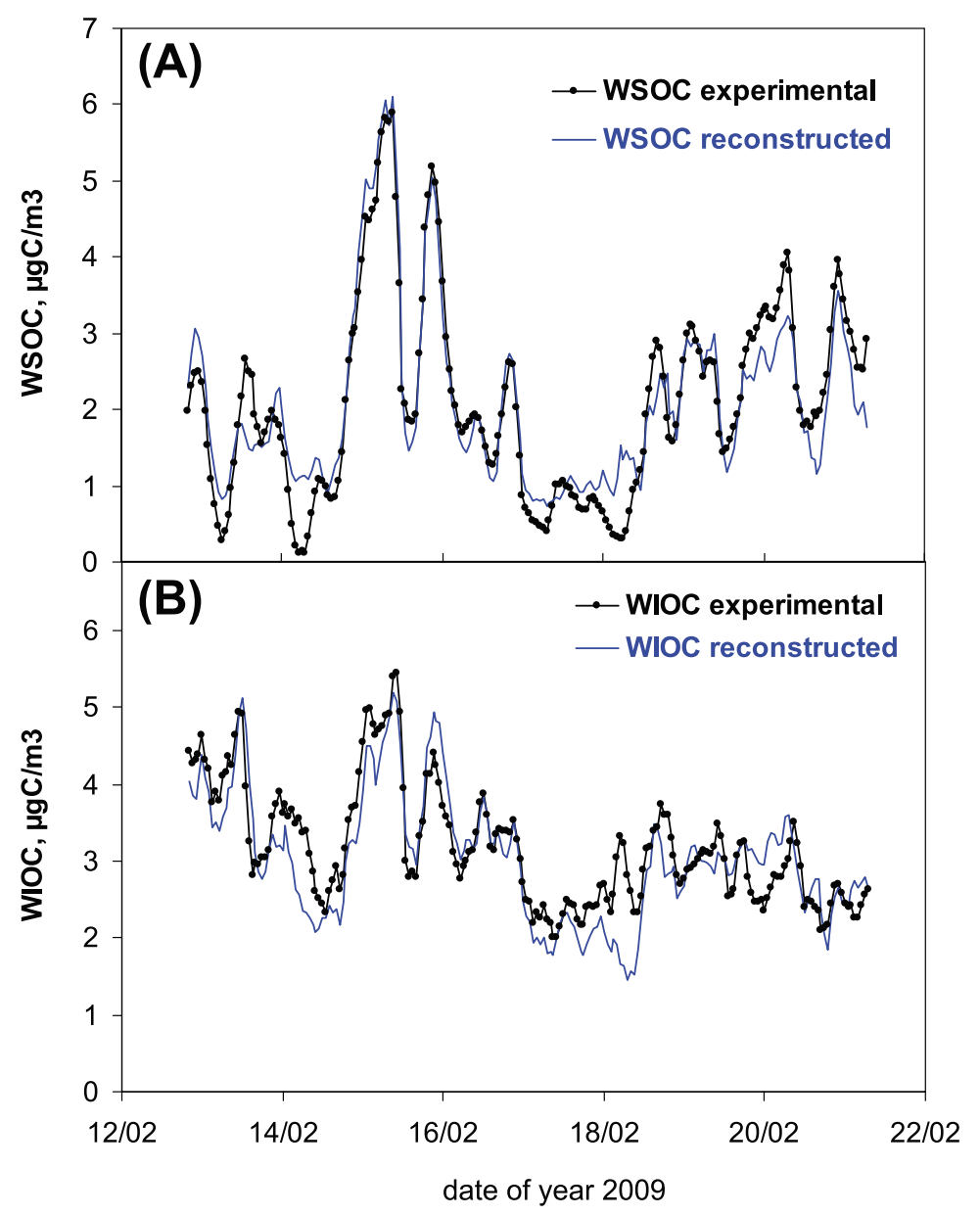

Figure 9. Comparison between experimentally determined (OCEC Sunset Field and PILS-TOC instruments) and reconstructed (aethalometer model) concentrations of (a) WSOC and (b) WIOC.

\subsubsection{The $\mathrm{m}$,p-xylenes}

[58] Hourly concentrations of this compound measured by the automatic GC-FID instrument are reported in Figure $8 \mathrm{~b}$ together with $\mathrm{BC}_{\mathrm{ff}}$. This compound was used here to trace the fossil fuel source as reported by Gaimoz et al. [2011] from a VOC source apportionment study in Paris. A very good agreement was found between $\mathrm{m}, \mathrm{p}$-xylenes and $\mathrm{BC}_{\mathrm{ff}}$ $\left(\mathrm{r}^{2}=0.74 ; \mathrm{N}=174\right)$ bringing further evidence of the ability of the aethalometer model to determine the fossil fuel source.

\subsection{Comparison of the Aethalometer Model Results With WSOC and WIOC Data Sets}

[59] In order to better document the water-soluble properties of SOA, a source apportionment of WSOC can be performed using a multilinear regression analysis and the 3 OA sources (wood burning, fossil fuel, residual) which have been determined previously by the aethalometer model. Results can be expressed as:

$$
\begin{aligned}
{[\mathrm{WSOC}]_{\text {reconstructed }}=} & {[\mathrm{WSOC}]_{\mathrm{ff}}+[\mathrm{WSOC}]_{\mathrm{wb}}+[\mathrm{WSOC}]_{\text {residual }} } \\
= & (0.005 \pm 0.043) \times\left[\mathrm{OM}_{\mathrm{ff}}\right]+(0.439 \pm 0.014) \\
& \times\left[\mathrm{OM}_{\mathrm{wb}}\right]+(0.079 \pm 0.010) \times\left[\mathrm{OM}_{\text {residual }}\right]
\end{aligned}
$$

Similarly a source apportionment of WIOC can be performed following the same methodology:

$$
\begin{aligned}
{[\mathrm{WIOC}]_{\text {reconstructed }}=} & {[\mathrm{WIOC}]_{\mathrm{ff}}+[\mathrm{WIOC}]_{\mathrm{wb}}+[\mathrm{WIOC}]_{\text {residual }} } \\
= & (0.227 \pm 0.045) \times\left[\mathrm{OM}_{\mathrm{ff}}\right]+(0.139 \pm 0.011) \\
& \times\left[\mathrm{OM}_{\mathrm{wb}}\right]+(0.464 \pm 0.009) \times\left[\mathrm{OM}_{\text {residual }}\right]
\end{aligned}
$$

Table 3. Source Apportionment Results for WSOC and WIOC From the Three OA Sources (Wood Burning, Fossil Fuel, Residual) Estimated by the Aethalometer Model ${ }^{\mathrm{a}}$

\begin{tabular}{lccc}
\hline Compound & Wood Burning & Fossil Fuel & Residual \\
\hline WSOC $\left(\mu \mathrm{gC} / \mathrm{m}^{3}\right)$ & $1.72 \pm 1.14(0.24-5.62)$ & $0.005 \pm 0.003(0.001-0.018)$ & $0.39 \pm 0.12(0.12-0.79)$ \\
WIOC $\left(\mu \mathrm{gC} / \mathrm{m}^{3}\right)$ & $0.54 \pm 0.36(0.07-1.78)$ & $0.23 \pm 0.16(0.02-0.84)$ & $2.26 \pm 0.72(0.70-4.63)$ \\
\hline
\end{tabular}

\footnotetext{
${ }^{a}$ Results are expressed as mean concentrations \pm 1 standard deviation $(\sigma)$; ranges are reported in brackets.
} 


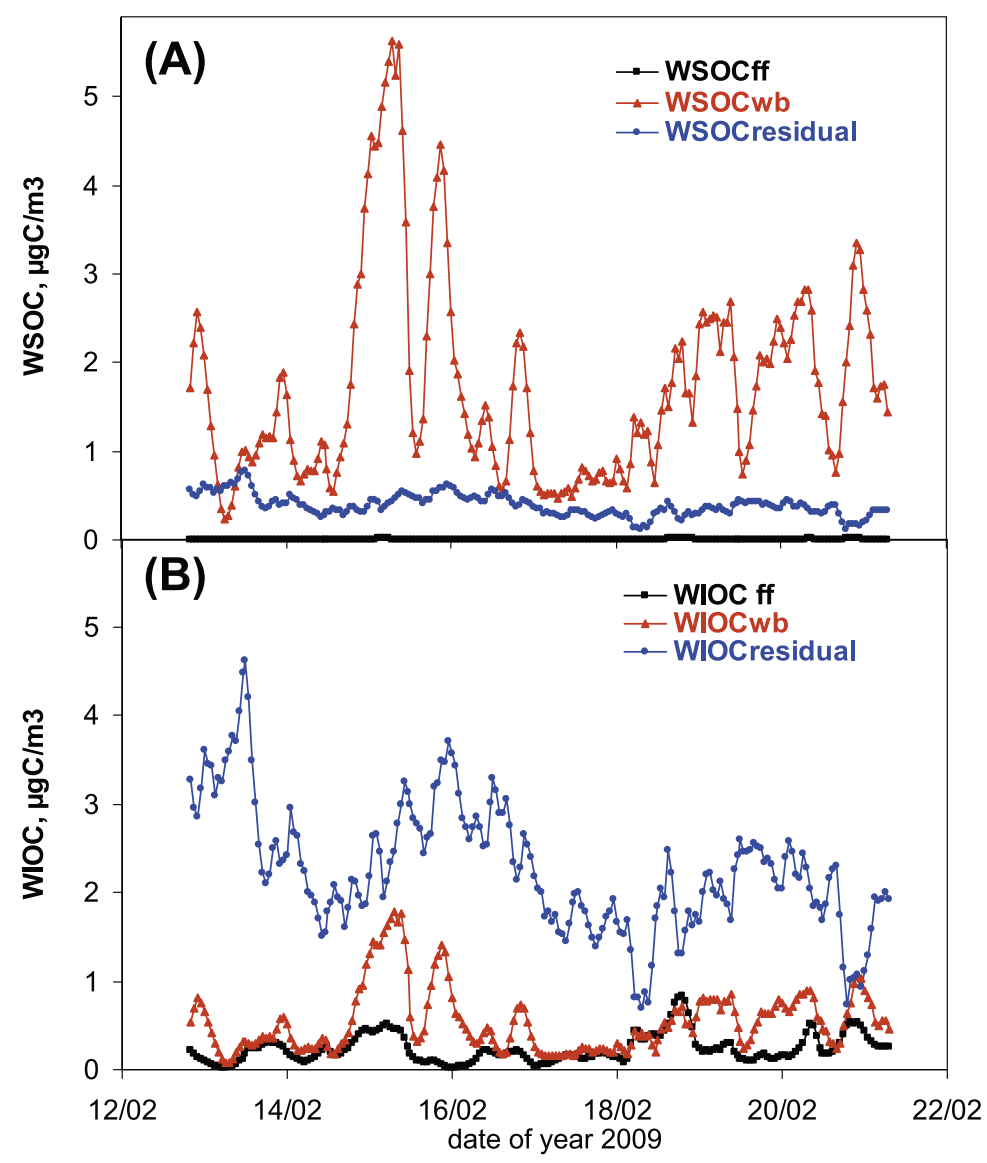

Figure 10. Temporal variation of (a) water-soluble and (b) water-insoluble organic aerosol concentrations from the 3 sources (fossil fuel, wood burning, and SOA) determined by the aethalometer model.

Temporal variations of measured and reconstructed WSOC and WIOC are reported in Figures 9a and 9b, respectively. Comparison between measured and reconstructed data sets shows significant correlation with $\mathrm{r}^{2}=0.87$ and $\mathrm{r}^{2}=0.73$ for WSOC and WIOC, respectively. Therefore, it can be assumed that the $3 \mathrm{OA}$ sources obtained with the aethalometer model are sufficient to explain most of the temporal variability of both WSOC and WIOC. Results of this source apportionment are summarized in Table 3 and show that $77 \%$ of our WSOC was originating from wood burning; the rest $(23 \%$ of WSOC) was assigned as residual (secondary). Negligible concentrations of WSOC from fossil fuel was found here, which is consistent with literature data on OA emissions from fossil fuel which are composed of poorly oxidized, therefore poorly water-soluble OA [Weber et al., 2007]. WIOC was found to be composed of fossil fuel (8\%), wood burning (17\%) and residual (75\%). Hourly concentrations of WSOC and WIOC from the 3 OA sources are reported in Figures 10a and 10b, respectively. Figure 10 clearly shows that WIOC and WSOC have very different contributions for each of the 3 sources. Therefore, there is a clear interest to better understand the water-soluble properties of OA as they may bring new insights in particular on the origin of SOA.

[60] We have also performed the source apportionment of WSOC and WIOC using the aethalometer model with the reconstruction of TC (see section 4.3). Results are reported in the auxiliary material in Figure S3 and lead to very similar results compared to those obtained using $\mathrm{CM}$ reconstruction. Some discrepancies are observed for the water-insoluble fossil fuel source (mean concentration of $0.78 \mu \mathrm{gC} / \mathrm{m} 3$ for the $\mathrm{TC}$ reconstruction instead of $0.51 \mu \mathrm{gC} / \mathrm{m} 3$ for the $\mathrm{CM}$ reconstruction). The other sources are almost identical. In conclusion, the use of TC (instead of $\mathrm{CM}$ ) leads to very similar results in the source apportionment of WSOC and WIOC made here with the 3 OA sources. The water-soluble properties of the $3 \mathrm{OA}$ sources (fossil fuel, biomass burning, and SOA) are presented and discussed below in more details.

\section{Discussion}

\subsection{Water-Soluble Properties of Biomass Burning Organic Aerosols $\left(\mathrm{OM}_{\mathrm{wb}}\right)$}

[61] Based on equations (13) and (14), $82 \pm 5 \%$ of $\mathrm{OC}_{\mathrm{wb}}$ can be assigned as water-soluble in agreement with literature data [Mayol-Bracero et al., 2002; Sullivan and Weber, 2006a; Yang et al., 2009]. This is consistent with the close relationship observed between $\mathrm{OM}_{\mathrm{wb}}$ and WSOC $\left(\mathrm{r}^{2}=0.87\right.$; $\mathrm{N}=204)$. It is interesting to note that the low dispersion $(5 \%)$ around the average value of $82 \%$ suggest a relatively constant contribution of WSOC to OA from wood burning during this study, independently of combustion processes (flaming/smoldering). 


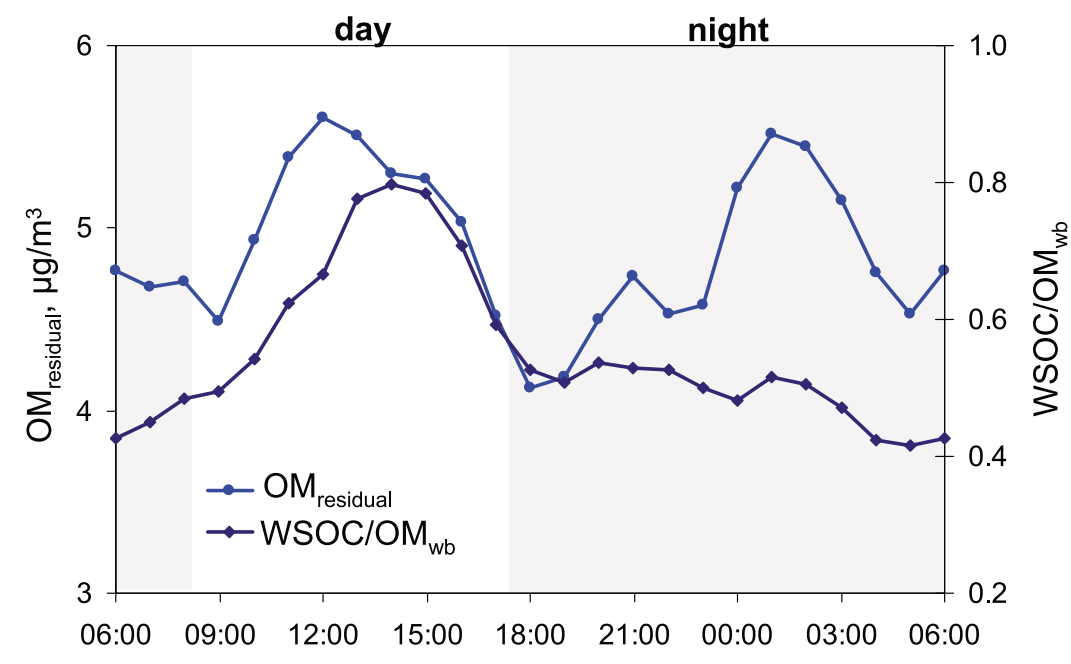

Local time

Figure 11. Diurnal variations of residual organic matter $\left(\mathrm{OM}_{\text {residual, }}\right.$, i.e., $\left.\mathrm{SOA}\right)$ and the $\left(\mathrm{WSOC} / \mathrm{OM}_{\mathrm{wb}}\right)$ ratio. The gray zones stand for nighttime.

\subsection{Water-Soluble Properties of Fossil Fuel Organic Aerosols $\left(\mathbf{O M}_{\mathrm{ff}}\right)$}

[62] Results reported in Table 3 show that our fossil fuel emissions are almost exclusively composed of WIOC. This result is in agreement with those reported in Tokyo by Miyazaki et al. [2006] and Kondo et al. [2007] who have noticed a strong correlation between WIOC and motor vehicle emission tracers $(\mathrm{EC}, \mathrm{CO})$. A strong connection between WIOC and hydrogen-like organic aerosols (HOA) derived by AMS measurements was also observed in Tokyo in which HOA can refer to POA from fossil fuel emissions [Zhang et al., 2005; Lanz et al., 2007].

\subsection{Water-Soluble Properties of SOA (OM residual $)$}

\subsubsection{Contribution of WSOC to SOA}

[63] Although wood burning has shown to be a major contributor of WSOC, other sources may have contributed to the levels of WSOC, in particular secondary organic formation. A $23 \%\left(0.39 \pm 0.12 \mu \mathrm{gC} / \mathrm{m}^{3}\right)$ contribution of the residual (secondary) organic source is assigned here as water-soluble. In order to support this result showing that there must be secondary production of WSOC and it is likely from the residual source, we have reported in Figure 11 the diurnal variations of the ratio between WSOC (directly measured by the PILS-TOC instrument) and $\mathrm{OM}_{\mathrm{wb}}$ (derived from the aethalometer model). Any increase of this WSOC/ $\mathrm{OM}_{\mathrm{wb}}$ ratio should be interpreted as a secondary production of WSOC. The diurnal variation of this $\mathrm{WSOC} / \mathrm{OM}_{\mathrm{wb}}$ ratio shows rather stable ratios close to 0.5 which are observed during the evening peak of domestic heating and during the rest of the night (18:00-08:00 LT). This suggests that WSOC is mainly originating from wood burning during this period. However, a significant increase in this ratio is observed during daytime with maximum values in the afternoon, with ratio values $75 \%$ higher compared to those observed during the wood burning period. An extra (residual) water-soluble OA source is needed to explain such increase which may be attributed to secondary (photochemical) pro- duction of WSOC during daytime. Note that this daytime maximum is fully consistent with the one calculated independently from the diurnal variation of our residual $\mathrm{OA}$ source (Figure 11).

[64] Several sources can be proposed to explain this secondary production of WSOC during daytime. Source dilution experiments have shown that a large fraction of primary $\mathrm{OM}_{\mathrm{wb}}$ is semi-volatile [Lipsky and Robinson, 2006; Shrivastava et al., 2006]; more than half of primary $\mathrm{OM}_{\mathrm{wb}}$ being evaporated at $50^{\circ} \mathrm{C}$ [Grieshop et al., 2009b]. Such dilution could occur during daytime and originate from the combining of reduction of wood burning emissions, PBL development, and/or changes in thermodynamic equilibrium during daytime. This may induce a change in the partitioning between water-soluble and water-insoluble $\mathrm{OA}$ fractions in wood burning, resulting in higher $\mathrm{WSOC} / \mathrm{OM}_{\mathrm{wb}}$ ratios during the day (Figure 11). Alternatively, photochemical oxidation of wood burning gas precursors can also be proposed since recent laboratory studies (performed on wood burning emissions under plume-like conditions) could produce substantial new $\mathrm{OA}$, increasing $\mathrm{OM}_{\mathrm{wb}}$ concentrations by a factor of 1.5 to 2.8 after several hours of exposure to typical summertime hydroxyl radical $(\mathrm{OH})$ concentrations [Grieshop et al., 2009a].

[65] Anthropogenic water-soluble SOA could also be formed here and explain the daytime maximum observed in the $\mathrm{WSOC} / \mathrm{OM}_{\mathrm{wb}}$ ratio. Several studies have noted correlations between OOA determined by AMS and other aerosol species attributed to secondary sources, notably sulfate and nitrate. This would indicate a similarity in the (anthropogenic) emissions of precursors and (photochemical) formation of such species [Lanz et al., 2007, 2008; Zhang et al., 2007]. Comparison has been performed for that purpose using ammonium (PILS-IC) as an indicator of the abundance of sulfate and nitrate, and the difference $\left(\mathrm{WSOM}^{\left.-\mathrm{OM}_{\mathrm{wb}}\right)}\right.$ as an estimate of water-soluble SOA. No clear relationship was observed here in these 2 data sets (data not shown), suggesting different emissions and/or formations. 


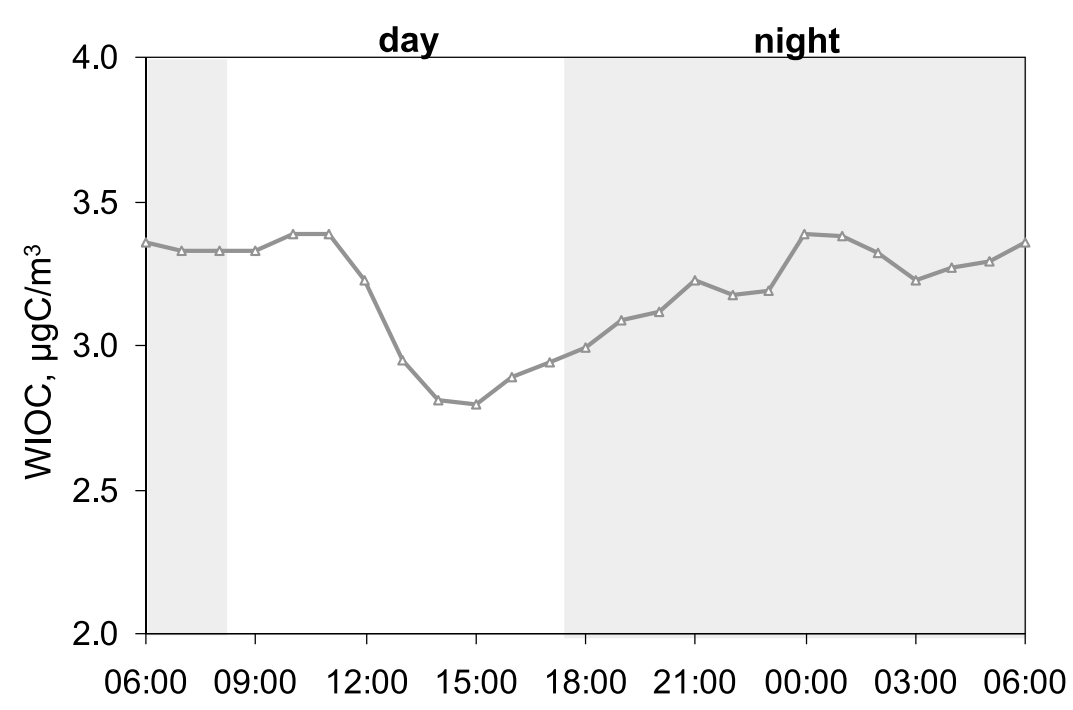

\section{Local time}

Figure 12. Diurnal variations of water-insoluble organic carbon (WIOC). The gray zones stand for nighttime.

[66] Although biogenic emissions are considerably reduced during wintertime, they still can contribute to SOA formation. Based on ${ }^{14} \mathrm{C}$ analyses and source apportionment of primary (wood burning and fossil fuel) organic sources in Sweden, Szidat et al. [2009] have reported the existence of a biogenic source of SOA during wintertime, with concentration levels ranging from 0.46 to $0.91 \mu \mathrm{gC} / \mathrm{m}^{3}$, the highest concentrations being observed over a period characterized by continental air masses. These results, together with the assumption that biogenic SOA are mainly watersoluble [Weber et al., 2007, and references therein] can be proposed to explain our increase of WSOC (relative to $\mathrm{OM}_{\mathrm{wb}}$ ) during the afternoon.

\subsubsection{Contribution of WIOC to SOA}

[67] Our results indicate that as much as $\sim 85 \%$ of $\mathrm{OM}_{\text {residual }}$ was water-insoluble. As reported previously, PBOA (which can be considered mainly as water-insoluble) are likely to play a negligible role here in $\mathrm{OM}_{\text {residual. }}$. For that reason, it can reasonably be assumed that most of our water-insoluble $\mathrm{OM}_{\text {residual }}$ is of secondary origin. These water-insoluble SOA can be formed through gas-to-particle conversion processes involving products of reactive organic gases although heterogeneous (aqueous phase) reactions leading to less water-soluble oligomers cannot be ruled out [Altieri et al., 2008]. Secondary formation of water-insoluble SOA could be the result of weak photochemical activity occurring during winter; leading to less oxidized (i.e., less watersoluble) SOA.

[68] By contrast with water-soluble SOA which shows a clear maximum during daytime, the diurnal pattern of WIOC reported in Figure 12 is weakly pronounced and shows only a slight decrease during daytime probably due to
PBL development. Such poor temporal variability could suggest a long range transport origin rather than a local pattern for WIOC. Back-trajectory analysis was performed for that purpose and results are reported in Figure 13 together with water-insoluble SOA variations. Periods with higher water-insoluble SOA concentrations are characterized by continental air masses, whereas lower concentrations are more related to marine air masses. Marine contribution may poorly contribute to the WIOC levels during the winter period [O'Dowd et al., 2004, Sciare et al., 2009]. Therefore, our results are consistent with a major continental origin for water-insoluble SOA.

[69] In order to better characterize the secondary origin of our residual WIOC, we have investigated the relationship between this fraction and specific oxygenated VOCs measured by PTR-MS that were not significantly affected by biomass burning and could be used to trace photochemical processes. A general good agreement was found between residual WIOC and acetone (Figure 13), with most of time concomitant maxima and minima. Based on a detailed source apportionment performed in Paris during springtime, Gaimoz et al. [2011] have found that acetone was associated with a photochemically processed industrialized source originated from Central and Eastern Europe. This result is consistent with those reported in Figure 13 which shows high values of acetone for continental air masses. They are also consistent with those reported by the literature which has shown important anthropogenic sources of acetone in the northern hemisphere [Jacob et al., 2005; Filella and Penuelas., 2006] originating from a secondary production by the oxidation of NMHC [Holzinger et al., 2005; Legreid et al., 2007]. All these results are in line

Figure 13. Temporal variation of residual WIOC (i.e., water-insoluble SOA) and acetone. Periods noted 1, 3, and 5 (in red) are characterized by continental air masses as shown by the red back trajectory plots reported in the 3 maps above the figure. Periods noted 2 and 4 (in blue) are characterized by marine air masses as shown by the blue back trajectory plots in the 2 maps below the figure. 

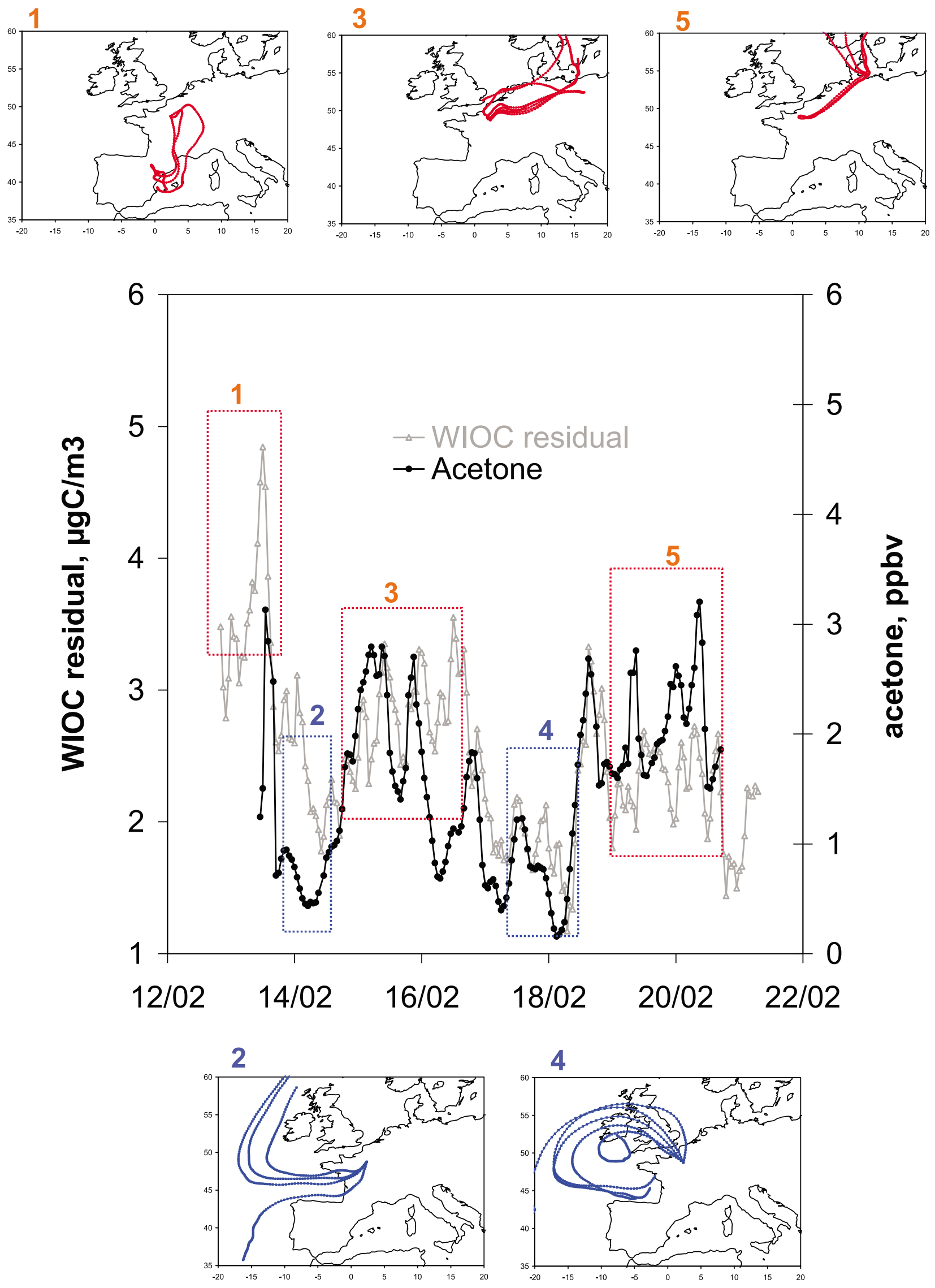

Figure 13 
with our assumption that residual WIOC is mainly composed of water-insoluble SOA. However, the origin of this secondary fraction still remains uncertain. Condensation of biomass burning semi-volatile species can be proposed here since the concentration levels of this source are particularly important during our study. Our results can also be compared with those reported by Robinson et al. [2007] who proposed that a substantial amount of SOA may originate from the condensation of aged semi-volatile anthropogenic POA composed of long chains of hydrocarbons which can be assumed as mainly water-insoluble. Such an assumption is supported by a number of recent studies which clearly show that anthropogenic VOCs lead to much more SOA than expected [de Gouw et al., 2005; Volkamer et al., 2006] suggesting unknown production pathways. Photochemical formation of water-insoluble SOA have already been reported in literature by Favez et al. [2008] in a semi-arid urban environment poorly affected by biogenic emissions, suggesting a possible anthropogenic contribution for SOA. Water-insoluble SOA have also been reported by Kondo et al. [2007] who showed that a small fraction of OOA (derived from AMS measurements) could be water-insoluble in Tokyo (Japan). Finally, it is worth noting here that significantly high levels of anthropogenic secondary organic carbon have recently been reported by Gilardoni et al. [2011] at a European rural site located in Northern Italy during the winter period $\left(2.2 \mu \mathrm{gC} / \mathrm{m}^{3}\right)$ supporting our observations of a significant source of SOA mainly being water-insoluble.

[70] Although the role of biogenic emissions cannot be excluded, primary sources (wood burning and anthropogenic emissions) appear to be good candidates to explain our large concentrations of water-insoluble SOA since their emissions are particularly high during winter. This result indicates that the oxidation of intermediate volatility organic compounds co-emitted with primary organics is a significant source of SOA, as suggested by AMS measurements in anthropogenically influenced Northern Hemisphere areas [Zhang et al., 2007]. As a whole, these results bring a new light on SOA which have been generally assigned as water-soluble.

\section{Conclusions}

[71] A large set of near real-time instruments have been deployed at a suburban site in the region of Paris (France) during wintertime in order to characterize fine carbonaceous aerosols (A.D. $<2.5 \mu \mathrm{m}$ ) and volatile organic compounds (VOC). Comparisons of EC, OC, and WSOC between online instruments (OCEC Sunset Field and PILS-TOC instruments) and VOC-denuded filter-based measurements were very satisfactory, pointing out the ability of our online instruments to provide reliable information on fast changes in ambient OA concentrations.

[72] A modified aethalometer model [Sandradewi et al., 2008a] applied to semi-continuous measurements of EC and $\mathrm{OC}$ was used to derive 3 sources of OA (fossil fuel, wood burning, and secondary). This source apportionment was tested for primary OA (fossil fuel, wood burning) against real-time measurements of tracers commonly used for these combustion sources (levoglucosan, water-soluble potassium, and methanol for wood burning; nitrogen oxide and $\mathrm{m}, \mathrm{p}$-xylenes for fossil fuel). A good agreement was obtained from these comparisons, giving further confidence on the results of the aethalometer model to properly determine primary OA. Residual OA (i.e., SOA) showed significant concentration levels during our study, ranging from 1.3 to $10.4 \mu \mathrm{g} / \mathrm{m}^{3}$ (average $5.38 \pm 1.33 \mu \mathrm{g} / \mathrm{m}^{3}$ ) and represented the most abundant OA species during our study.

[73] Hourly measurements of WSOC and WIOC were obtained during our study using the PILS-TOC and OCEC Sunset Field instruments. A source apportionment of these 2 fractions was performed using the 3 OA sources obtained with the aethalometer model providing useful information on the water-soluble properties of these different $\mathrm{OA}$ sources. A very large fraction $(82 \pm 5 \%)$ of OC originating from wood burning could be assigned as water-soluble in agreement with literature data. A negligible amount of fossil fuel OA $(<1 \%)$ was identified as water-soluble, which is also consistent with primary OA from fossil fuel emissions being poorly oxidized and thus mainly water-insoluble. About $23 \%$ of WSOC was found to be of secondary origin, with a clear diurnal pattern showing a maximum during daytime linked to local photochemical production.

[74] Less expected is the large fraction of secondary organic carbon $(\sim 85 \%)$ identified as water-insoluble. This fraction did not show an important diurnal variation suggesting a weak local (photochemical) production, and pointing to a more regional (long range transport) origin. This is consistent with back trajectory analysis which revealed that the highest water-insoluble SOA concentrations were observed for continental air masses. The poor contribution of biogenic SOA during wintertime and its water-soluble properties suggest that our water-insoluble SOA may originate from semi-volatile primary combustion emissions (fossil fuel, wood burning). Modern versus fossil fuel source apportionment of carbonaceous aerosols would aid the conclusions presented here. An independent estimate of SOA and its oxygen content - using an AMS may also considerably contribute to better depicting wintertime SOA levels and oxidation state.

[75] These results bring new light on the commonly accepted idea that SOA is mainly water-soluble. They have been obtained at a typical suburban site of France and may be then representative of a larger European area. They also have important implications for the SOA lifetime which is partly controlled by removal processes in which the watersoluble properties play an important role.

[76] Acknowledgments. This work is a contribution to the ANRAEROCOV program. It was funded by ANR, ADEME, CEA, and CNRS. J. Williams, T. Custer and T. Kluepfel from the Max Planck Institute (Mainz, Germany) are gratefully thanked for their help with the PTR-MS calibration. AIRPARIF is thanked here for their contribution in NO measurements.

\section{References}

Altieri, K. E., S. P. Seitzinger, A. G. Carlton, B. J. Turpin, G. C. Klein, and A. G. Marshall (2008), Oligomers formed through in-cloud methylglyoxal reactions: Chemical composition, properties, and mechanisms investigated by ultra-high resolution FT-ICR mass spectrometry, Atmos. Environ., 42, 1476-1490, doi:10.1016/j.atmosenv.2007.11.015.

Bae, M.-S., J. J. Schauer, J. T. DeMinter, J. R. Turner, D. Smith, and R. A. Cary (2004), Validation of a semi-continuous instrument for elemental, carbon and organic carbon using a thermal-optical method, Atmos. Environ., 38, 2885-2893, doi:10.1016/j.atmosenv.2004.02.027. 
Bauer, H., A. Kasper-Giebl, F. Zibuschka, R. Hitzenberger, G. Kraus, and H. Puxbaum (2002), Determination of the carbon content of airborne fungal spores, Anal. Chem., 74, 91-95, doi:10.1021/ac010331+.

Bauer, H., E. Schueller, G. Weinke, A. Berger, R. Hitzenberger, I. L. Marr, and H. Puxbaum (2008a), Significant contributions of fungal spores to the organic carbon and to the aerosol mass balance of the urban atmospheric aerosol, Atmos. Environ., 42, 5542-5549, doi:10.1016/j.atmosenv. 2008.03.019.

Bauer, H., M. Claeys, R. Vermeylen, E. Schueller, G. Weinke, A. Berger, and H. Puxbaum (2008b), Arabitol and mannitol as tracers for the quantification of airborne fungal spores, Atmos. Environ., 42, 588-593, doi:10.1016/j.atmosenv.2007.10.013.

Birch, M. E., and R. A. Cary (1996), Elemental carbon-based method for monitoring occupational exposures to particulate diesel exhaust, Aerosol Sci. Technol., 25, 221-241, doi:10.1080/02786829608965393.

Blake, R. S., P. S. Monks, and A. M. Ellis (2009), Proton-Transfer Reaction Mass Spectrometry, Chem. Rev., 109, 861-896, doi:10.1021/ cr800364q.

Bond, T. C., and R. W. Bergstrom (2006), Light absorption by carbonaceous particles: An investigative review, Aerosol Sci. Technol., 40, 27-67, doi:10.1080/02786820500421521.

Bonsang, B., B. Al Aarbaoui, and J. Sciare (2008), Diurnal variation of non methane hydrocarbons in the subantarctic atmosphere, Environ. Chem. 5, 16-23, doi:10.1071/EN07018.

Clarke, A., et al. (2007), Biomass burning and pollution aerosol over North America: Organic components and their influence on spectral optica properties and humidification response, J. Geophys. Res., 112 D12S18, doi:10.1029/2006JD007777.

Collaud Coen, M., et al. (2010), Minimizing light absorption measurement artifacts of the aethalometer: Evaluation of five correction algorithms, Atmos. Meas. Tech., 3, 457-474, doi:10.5194/amt-3-457-2010.

Decesari, S., M. C. Facchini, E. Matta, F. Lettini, M. Mircea, S. Fuzzi, E. Tagliavini, and J.-P. Putaud (2001), Chemical features and seasonal variation of fine aerosol water-soluble organic compounds in the Po Valley, Italy, Atmos. Environ., 35, 3691-3699, doi:10.1016/S1352-2310(00) 00509-4.

de Gouw, J., and C. Warneke (2007), Measurements of volatile organic compounds in the earths atmosphere using proton-transfer-reaction mass spectrometry, Mass Spectrom. Rev., 26, 223-257, doi:10.1002/ mas.20119.

de Gouw, J. A., et al. (2005), The budget of organic carbon in a polluted atmosphere: Results from the New England Air Quality Study in 2002 , J. Geophys. Res., 110, D16305, doi:10.1029/2004JD005623.

de Gouw, J. A., et al. (2006), Volatile organic compounds composition of merged and aged forest fire plumes from Alaska and western Canada, J. Geophys. Res., 111, D10303, doi:10.1029/2005JD006175.

Eatough, D. J., A. Wadsworth, D. A. Eatough, J. W. Crawford, L. D. Hansen, and E. A. Lewis (1993), A multiple system, multi-channel diffusion denuder sampler for the determination of fine-particulate organic material in the atmosphere, Atmos. Environ. Part A, 27, 1213-1219, doi:10.1016/09601686(93)90247-V

El Haddad, I., et al. (2009), Comprehensive primary particulate organic characterization of vehicular exhaust emissions in France, Atmos. Environ. 43(39), 6190-6198, doi:10.1016/j.atmosenv.2009.09.001

Favez, O., H. Cachier, J. Sciare, and Y. Le Moullec (2007), Semi-volatile aerosols in Paris (France): Characterization and contribution to $\mathrm{PM}_{2.5}$, Atmos. Environ., 41, 7969-7976, doi:10.1016/j.atmosenv.2007.09.031.

Favez, O., J. Sciare, H. Cachier, S. C. Alfaro, and M. M. Abdelwahab (2008), Significant formation of water-insoluble secondary organic aerosols in semi-arid urban environment, Geophys. Res. Lett., 35, L15801, doi:10.1029/2008GL034446.

Favez, O., H. Cachier, J. Sciare, R. Sarda-Estève, and L. Martinon (2009), Evidence for a significant contribution of wood burning aerosols to $\mathrm{PM}_{2.5}$ during the winter season in Paris, France, Atmos. Environ., 43, 3640-3644, doi:10.1016/j.atmosenv.2009.04.035

Favez, O., et al. (2010), Inter-comparison of source apportionment models for the estimation of wood burning aerosols during wintertime in an Alpine city (Grenoble, France), Atmos. Chem. Phys., 10, 5295-5314., doi:10.5194/acp-10-5295-2010.

Fialho, P., A. D. A. Hansen, and R. E. Honrath (2005), Absorption coefficients by aerosols in remote areas: A new approach to decouple dust and black carbon absorption coefficients using seven-wavelength aethalometer data, J. Aerosp. Sci., 36(2), 267-282, doi:10.1016/j.jaerosci. 2004.09.004.

Filella, I., and J. Penuelas (2006), Daily, weekly, and seasonal time courses of VOC concentrations in a semi-urban area near Barcelona, Atmos. Environ., 40, 7752-7769, doi:10.1016/j.atmosenv.2006.08.002.

Gaeggeler, K., A. S. H. Prévôt, J. Dommen, G. Legreid, S. Reimann, and U. Baltensperger (2008), Residential wood burning in an Alpine valley as a source for oxygenated volatile organic compounds, hydrocarbons and organic acids, Atmos. Environ., 42, 8278-8287, doi:10.1016/j.atmosenv. 2008.07.038

Gaimoz, C., et al. (2011), Volatile organic compounds sources in Paris in spring 2007. Part II: Source apportionment using positive matrix factorization, Environ. Chem., 8, 91-103, doi:10.1071/EN10067.

Gelencsér, A., B. May, D. Simpson, A. Sánchez-Ochao, A. Kasper-Giebl, H. Puxbaum, A. Caseiro, C. Pio, and M. Legrand (2007), Source apportionment of $\mathrm{PM}_{2.5}$ organic aerosol over Europe: Primary/secondary, natural/anthropogenic, fossil/biogenic origin, J. Geophys. Res., 112 D23S04, doi:10.1029/2006JD008094

Gilardoni, S., E. Vignati, F. Cavalli, J. P. Putaud, B. R. Larsen, M. Karl, K. Stenström, J. Genberg, S. Henne, and F. Dentener (2011), Better constraints on sources of carbonaceous aerosols using a combined 14C-macro tracer analysis in a European rural background site, Atmos. Chem. Phys. Discuss., 11, 2503-2547, doi:10.5194/acpd-11-2503-2011. Grieshop, A. P., N. M. Donahue, and A. L. Robinson (2009a), Laboratory investigation of photochemical oxidation of organic aerosol from wood fires 2: Analysis of aerosol mass spectrometer data, Atmos. Chem. Phys., 9, 2227-2240, doi:10.5194/acp-9-2227-2009.

Grieshop, A. P., J. M. Logue, N. M. Donahue, and A. L. Robinson (2009b), Laboratory investigation of photochemical oxidation of organic aerosol from wood fires 1: Measurement and simulation of organic aerosol evolution, Atmos. Chem. Phys., 9, 1263-1277, doi:10.5194/acp-9-1263-2009.

Gros, V., et al. (2011), Volatile organic compounds sources in Paris in spring 2007. Part I: Qualitative analysis, Environ. Chem., 8, 74-90, doi:10.1071/EN10068.

Grover, B. D., M. Kleinmain, N. L. Eathough, D. J. Eatough, P. K. Hopke, R. W. Long, W. E. Wilson, M. B. Meyer, and J. L. Ambs (2005), Measurement of total $\mathrm{PM}_{2.5}$ mass (non volatile plus semivolatile) with the Filter Dynamic Measurement System tapered element oscillating microbalance monitor, J. Geophys. Res., 110, D07S03, doi:10.1029/2004JD004995.

Heald, C. L., et al. (2006), Concentrations and sources of organic carbon aerosols in the free troposphere over North America, J. Geophys. Res. 111, D23S47, doi:10.1029/2006JD007705.

Hecobian, A., X. Zhang, M. Zheng, N. Frank, E. S. Edgerton, and R. J. Weber (2010), Water-Soluble Organic Aerosol material and the lightabsorption characteristics of aqueous extracts measured over the Southeastern United States, Atmos. Chem. Phys., 10, 5965-5977, doi:10.5194/acp-10-5965-2010.

Hennigan, C. J., M. H. Bergin, J. E. Dibb, and R. J. Weber (2008a), Enhanced secondary organic aerosol formation due to water uptake by fine particles, Geophys. Res. Lett., 35, L18801, doi:10.1029/ 2008GL035046.

Hennigan, C. J., et al. (2008b), On the volatility and production mechanisms of newly formed nitrate and water-soluble organic aerosol in Mexico City, Atmos. Chem. Phys., 8, 3761-3768, doi:10.5194/acp-8-3761-2008. Hennigan, C. J., A. P. Sullivan, J. L. Collett Jr., and A. L. Robinson (2010), Levoglucosan stability in biomass burning particles exposed to hydroxyl radicals, Geophys. Res. Lett., 37, L09806, doi:10.1029/2010GL043088. Hoffer, A., A. Gelencsér, P. Guyon, G. Kiss, O. Schmid, G. P. Frank, P. Artaxo, and M. O. Andreae (2006), Optical properties of humic-like substances (HULIS) in biomass burning aerosol, Atmos. Chem. Phys., 6 , 3563-3570, doi:10.5194/acp-6-3563-2006.

Holzinger, R., J. Williams, G. Salisbury, T. Klüpfel, M. de Reus, M. Traub, P. J. Crutzen, and J. Lelieveld (2005), Oxygenated compounds in aged biomass burning plumes over the Eastern Mediterranean: Evidence for strong secondary production of methanol and acetone, Atmos. Chem. Phys., 5, 39-46, doi:10.5194/acp-5-39-2005.

Iinuma, Y., G. Engling, H. Puxbaum, and H. Herrmann (2009), A highly resolved anion-exchange chromatographic method for determination of saccharidic tracers for biomass combustion and primary bio-particles in atmospheric aerosol, Atmos. Environ., 43, 1367-1371, doi:10.1016/j. atmosenv.2008.11.020

Jacob, D. J., B. D. Field, Q. B. Li, D. R. Blake, J. de Gouw, C. Warneke, A. Hansel, A. Whisthaler, H. B. Singh, and A. Guenther (2005), Global budget of methanol: Constraints from atmospheric observations, J. Geophys. Res., 110, D08303, doi:10.1029/2004JD005172.

Jeong, C.-H., et al. (2008), Influence of biomass burning on wintertime fine particulate matter: Source contribution at a valley site in rural British Columbia, Atmos. Environ., 42, 3684-3699, doi:10.1016/j.atmosenv. 2008.01.006.

Jiang, M., et al. (2005), Vehicle fleet emissions of black carbon, polycyclic aromatic hydrocarbons, and other pollutants measured by a mobile laboratory in Mexico City, Atmos. Chem. Phys., 5, 3377-3387, doi:10.5194/ acp-5-3377-2005

Karl, T. G., T. J. Christian, R. J. Yokelson, P. Artaxo, W. M. Hao, and A. Guenther (2007), The Tropical Forest and Fire Emissions Experiment: Method evaluation of volatile organic compound emissions measured by 
PTR-MS, FTIR, and GC from tropical biomass burning, Atmos. Chem. Phys., 7, 5883-5897, doi:10.5194/acp-7-5883-2007.

Kirchstetter, T. W., T. Novakok, and P. V. Hobbs (2004), Evidence that the spectral dependence of light absorption by aerosols is affected by organic carbon, J. Geophys. Res., 109, D21208, doi:10.1029/2004JD004999.

Kiss, G., B. Varga, I. Galambos, and I. Ganszky (2002), Characterization of water-soluble organic matter isolated from atmospheric fine aerosol, J. Geophys. Res., 107(D21), 8339, doi:10.1029/2001JD000603.

Kondo, Y., Y. Miyazaki, N. Takegawa, T. Miyakawa, R. J. Weber, J. L. Jimenez, Q. Zhang, and D. R. Worsnop (2007), Oxygenated and water-soluble organic aerosols in Tokyo, J. Geophys. Res., 112, D01203, doi:10.1029/2006JD007056.

Kupiainen, K., and Z. Klimont (2007), Primary emissions of fine carbonaceous particles in Europe, Atmos. Environ., 41, 2156-2170, doi:10.1016/ j.atmosenv.2006.10.066.

Lack, D., et al. (2008), Bias in filter-based aerosol light absorption measurements due to organic aerosol loading: Evidence from ambient measurements, Aerosol Sci. Technol., 42, 1033-1041, doi:10.1080/ 02786820802389277.

Lanz, V. A., M. R. Alfarra, U. Baltensperger, B. Buchmann, C. Hueglin, and A. S. H. Prévôt (2007), Source apportionment of submicron organic aerosols at an urban site by factor analytical modelling of aerosol mass spectra, Atmos. Chem. Phys., 7, 1503-1522, doi:10.5194/acp-7-15032007.

Lanz, V. A., et al. (2008), Source attribution of submicron organic aerosols during wintertime inversions by advanced factor analysis of aerosol mass spectra, Environ. Sci. Technol., 42, 214-220, doi:10.1021/es0707207.

Lanz, V. A., et al. (2010), Characterization of aerosol chemical composition with aerosol mass spectrometry in Central Europe: An overview, Atmos. Chem. Phys., 10, 10,453-10,471, doi:10.5194/acp-10-10453-2010.

Legreid, G., J. B. Lööv, J. Staehelin, C. Hueglin, M. Hill, B. Buchmann, A. S. H. Prévôt, and S. Reimann (2007), Oxygenated volatile organic compounds (OVOCs) at an urban background site in Zürich (Europe): Seasonal, variation and source allocation, Atmos. Environ., 41, 84098423, doi:10.1016/j.atmosenv.2007.07.026.

Lewis, K., W. P. Arnott, H. Moosmüller, and C. E. Wold (2008), Strong spectral variation of biomass smoke light absorption and single scattering albedo observed with a novel dual-wavelength photoacoustic instrument, J. Geophys. Res., 113, D16203, doi:10.1029/2007JD009699.

Lindinger, W., A. Hansel, and A. Jordan (1998), On-line monitoring of volatile organic compounds at pptv levels by means of proton-transferreaction mass spectrometry (PTR-MS) - Medical applications, food control and environmental research, Int. J. Mass Spectrom., 173, 191-241, doi:10.1016/S0168-1176(97)00281-4

Liousse, C., H. Cachier, and S. G. Jennings (1993), Optical and thermal measurements of black carbon aerosol content in different environmentsvariation of the specific attenuation cross section, sigma $(\sigma)$, Atmos. Environ., 27A, 1203-1211.

Lipsky, E. M., and A. L. Robinson (2006), Effects of dilution on fine particle mass and partitioning of semivolatile organics in diesel exhaust and wood smoke, Environ. Sci. Technol., 40(1), 155-162, doi:10.1021/ es050319p.

Lonati, G., S. Ozgen, and M. Giugliano (2007), Primary and secondary carbonaceous species in $\mathrm{PM}_{2.5}$ samples in Milan (Italy), Atmos. Environ., 41, 4599-4610, doi:10.1016/j.atmosenv.2007.03.046.

Lukács, H., et al. (2007), Seasonal trends and possible sources of brown carbon based on 2-year aerosol measurements at six sites in Europe, J. Geophys. Res., 112, D23S18, doi:10.1029/2006JD008151.

Mayol-Bracero, O. L., P. Guyon, B. Graham, G. Roberts, M. O. Andreae, S. Decesari, M. C. Facchini, S. Fuzzi, and P. Artaxo (2002), Water-soluble organic compounds in biomass burning aerosols over Amazonia: 2. Apportionment of the chemical composition and importance of the polyacidic fraction, J. Geophys. Res., 107(D20), 8091, doi:10.1029/ 2001JD000522.

Miyazaki, Y., Y. Kondo, N. Takegawa, Y. Komazaki, K. Kawamura, M. Mochida, K. Okuzawa, and R. J. Weber (2006), Time-resolved measurements of water-soluble organic carbon in Tokyo, J. Geophys. Res., 111, D23206, doi:10.1029/2006JD007125.

Nel, A. (2005), Air pollution-related illness: Effects of particles, Science, 308, 804-806, doi:10.1126/science.1108752.

O’Dowd, C. D., M. C. Facchini, F. Cavalli, D. Ceburnis, M. Mircea S. Decesari, S. Fuzzi, Y. J. Yoon, and J.-P. Putaud (2004), Biogenically driven organic contribution to marine aerosol, Nature, 431, 676-680, doi:10.1038/nature02959.

Orsini, D. A., Y. Ma, A. Sullivan, B. Sierau, K. Baumann, and R. J. Weber (2003), Refinements to the particle-into-liquid sampler (PILS) for ground and airborne measurements of water-soluble aerosol composition, Atmos. Environ., 37, 1243-1259, doi:10.1016/S1352-2310(02)01015-4.
Peltier, R. E., R. J. Weber, and A. P. Sullivan (2007), Investigating a liquid-based method for online organic carbon detection in atmospheric particles, Aerosol Sci. Technol., 41, 1117-1127, doi:10.1080/ 02786820701777465.

Puxbaum, H., A. Caseiro, A. Sánchez-Ochoa, A. Kasper-Giebl, M. Claeys, A. Gelencsér, M. Legrand, S. Preunkert, and C. Pio (2007), Levoglucosan levels at background sites in Europe for assessing the impact of biomass combustion on the European aerosol background, J. Geophys. Res., 112, D23S05, doi:10.1029/2006JD008114.

Ramanathan, V., et al. (2007), Atmospheric brown clouds: Hemispherical and regional variations in long range transport, absorption, and radiative forcing, J. Geophys. Res., 112, D22S21, doi:10.1029/2006JD008124.

Robinson, A. L., N. M. Donahue, M. K. Shrivastava, E. A. Weitkamp, A. M. Sage, A. P. Grieshop, T. E. Lane, J. R. Pierce, and S. N. Pandis (2007), Rethinking organic aerosols: Semivolatile emissions and photochemical aging, Science, 315(5816), 1259-1262, doi:10.1126/science.1133061.

Sandradewi, J., A. S. H. Prévôt, S. Szidat, N. Perron, M. R. Alfarra, V. A. Lanz, E. Weingartner, and U. Baltensperger (2008a), Using aerosol light absorption measurements for the quantitative determination of wood burning and traffic emission contributions to particulate matter, Environ. Sci. Technol., 42, 3316-3323, doi:10.1021/es702253m.

Sandradewi, J., A. S. H. Prévôt, E. Weingartner, R. Schmidhauser, M. Gysel, and U. Baltensperger (2008b), A study of wood burning and traffic aerosols in an Alpine valley using a multi-wavelength aethalometer, Atmos. Environ., 42, 101-112, doi:10.1016/j.atmosenv.2007.09.034.

Schnaiter, M., H. Horvath, O. Möhler, K. H. Naumann, and H. W. Saathoff (2003), UV-VIS-NIR spectral optical properties of soot and soot containing aerosols, J. Aerosol Sci., 34, 1421-1444, doi:10.1016/S0021-8502 (03)00361-6.

Schnaiter, M., et al. (2005), Measurement of wavelength-resolved light absorption by aerosols utilizing a UV-VIS extinction cell, Aerosp. Sci. Technol., 39, 249-260, doi:10.1080/027868290925958.

Sciare, J., H. Cachier, K. Oikonomou, P. Ausset, R. Sarda-Estève, and N. Mihalopoulos (2003), Characterization of carbonaceous aerosols during the MINOS campaign in Crete, July August 2001: A multi-analytical approach, Atmos. Chem. Phys., 3, 1743-1757, doi:10.5194/acp-3-17432003.

Sciare, J., H. Cachier, R. Sarda-Estève, T. Yu, and X. Wang (2007), Semivolatile aerosols in Beijing (R.P. China): Characterization and influence on various $\mathrm{PM}_{2.5}$ measurements, J. Geophys. Res., 112, D18202, doi:10.1029/2006JD007448.

Sciare, J., O. Favez, K. Oikonomou, R. Sarda-Estève, H. Cachier, and V. Kazan (2009), Long-term observation of carbonaceous aerosols in the Austral Ocean: Evidence of a marine biogenic origin, J. Geophys. Res., 114, D15302, doi:10.1029/2009JD011998.

Sciare, J., O. d'Argouges, Q. Zhang, R. Sarda-Estève, C. Gaimoz, V. Gros, M. Beekmann, and O. Sanchez (2010), Comparison between simulated and observed chemical composition of fine aerosols in Paris (France) during springtime: Contribution of regional versus continental emissions, Atmos. Chem. Phys., 10, 11,987-12,004, doi:10.5194/acp-10-11987-2010. Shrivastava, M. K., E. M. Lipsky, C. O. Stanier, and A. L. Robinson (2006), Modeling semivolatile organic aerosol mass emissions from combustion systems, Environ. Sci. Technol., 40(8), 2671-2677, doi:10.1021/ es0522231.

Sorooshian, A., F. Brechtel, Y. Ma, R. Weber, A. Corless, R. Flagan, and J. Seinfeld (2006), Modeling and Characterization of a Particle-intoLiquid Sampler (PILS), Aerosol Sci. Technol., 40(6), 396-409.

Sullivan, A. P., and R. J. Weber (2006a), Chemical characterization of the ambient organic aerosol soluble in water: 1 . Isolation of hydrophobic and hydrophilic fractions with a XAD-8 resin, J. Geophys. Res., 111, D05314, doi:10.1029/2005JD006485.

Sullivan, A. P., and R. J. Weber (2006b), Chemical characterization of the ambient organic aerosol soluble in water: 2. Isolation of acid, neutral, and basic fractions by modified size-exclusion chromatography, J. Geophys. Res., 111, D05315, doi:10.1029/2005JD006486.

Sullivan, A. P., R. J. Weber, A. L. Clements, J. R. Turner, M. S. Bae, and J. J. Schauer (2004), A method for on-line measurement of water-soluble organic carbon in ambient aerosol particles: Results from an urban site, Geophys. Res. Lett., 31, L13105, doi:10.1029/2004GL019681.

Sullivan, A. P., R. E. Peltier, C. A. Brock, J. A. de Gouw, J. S. Holloway, C. Warneke, A. G. Wollny, and R. J. Weber (2006), Airborne measurements of carbonaceous aerosol soluble in water over north-eastern United States: Method development and an investigation into water-soluble organic carbon sources, J. Geophys. Res., 111, D23S46, doi:10.1029/ 2006JD007072.

Sullivan, A. P., A. S. Holden, L. A. Patterson, G. R. McMeeking, S. M. Kreidenweis, W. C. Malm, W. M. Hao, C. E. Wold, and J. L. Collett Jr. (2008), A method for smoke marker measurements and its potential 
application for determining the contribution of biomass burning from wildfires and prescribed fires to ambient $\mathrm{PM}_{2.5}$ organic carbon, J. Geophys Res., 113, D22302, doi:10.1029/2008JD010216.

Szidat, S., M. Ruff, N. Perron, L. Wacker, H.-A. Synal, M. Hallquist, A. S. Shannigrahi, K. E. Yttri, C. Dye, and D. Simpson (2009), Fossil and nonfossil sources of organic carbon (OC) and elemental carbon (EC) in Göteborg, Sweden, Atmos. Chem. Phys., 9, 1521-1535, doi:10.5194/acp-9-1521-2009.

Turpin, B. J., and H. J. Lim (2001), Species contribution to $\mathrm{PM}_{2.5}$ mass concentrations: Revisiting common assumptions for estimating organic mass, Aerosol Sci. Technol., 35, 602-610.

Volkamer, R., J. L. Jimenez, F. S. Martini, K. Dzepina, Q. Zhang, D. Salcedo, L. T. Molina, D. R. Worsnop, and M. J. Molina (2006), Secondary organic aerosol formation from anthropogenic air pollution: Rapid and higher than expected, Geophys. Res. Lett., 33, L17811, doi:10.1029/2006GL026899.

Weber, R. J., et al. (2007), A study of secondary organic aerosol formation in the anthropogenic influenced southeastern United States, J. Geophys. Res., 112, D13302, doi:10.1029/2007JD008408.

Weingartner, E., H. Saathoff, M. Schnaiter, N. Streit, B. Bitnar, and U. Baltensperger (2003), Absorption of light by soot particles: Determination of the absorption coefficient by means of aethalometers, J. Aerosol Sci., 34, 1445-1463, doi:10.1016/S0021-8502(03)00359-8.
Yang, M., S. G. Howell, J. Zhuang, and B. J. Huebert (2009), Attribution of aerosol light absorption to black carbon, brown carbon, and dust in China-Interpretations of atmospheric measurements during EASTAIRE, Atmos. Chem. Phys. 9, 2035-2050, doi:10.5194/acp-9-2035-2009.

Zhang, Q., M. R. Alfarra, D. R. Worsnop, J. D. Allan, H. Coe, M. R. Canagaratna, and J. L. Jimenez (2005), Deconvolution and quantification of hydrocarbon-like and oxygenated organic aerosols based on aerosol mass spectrometry, Environ. Sci. Technol., 39, 4938-4952, doi:10.1021/es0485681.

Zhang, Q., J. L. Jimenez, M. R. Canagaratna, et al. (2007), Ubiquity and dominance of oxygenated species in organic aerosols in anthropogenically influenced Northern Hemisphere mid-latitudes, Geophys. Res. Lett., 34, L13801, doi:10.1029/2007GL029979.

N. Bonnaire, B. Bonsang, O. d'Argouges, C. Dolgorouky, C. Gaimoz, V. Gros, R. Sarda-Estève, and J. Sciare, Laboratoire des Sciences du Climat et de l'Environnement, CNRS-CEA-UVSQ, Orme des Merisiers, Bat. 701, F-91191 Gif-sur-Yvette, France. (jean.sciare@1sce.ipsl.fr)

O. Favez, Institut National de l'Environnement Industriel et des Risques, Parc Technologique Alata, F-60550 Verneuil-en-Halatte, France. 